\title{
Low-temperature plasma modification of carbon nanofillers for improved performance of advanced rubber composites
}

\author{
Mariusz Siciński ${ }^{1}$ D Dariusz M. Bieliński ${ }^{1} \cdot$ Hieronim Szymanowski ${ }^{2}$. \\ Tomasz Gozdek ${ }^{1} \cdot$ Anna Piątkowska ${ }^{3}$
}

Received: 6 July 2018 / Revised: 21 December 2018 / Accepted: 19 April 2019 / Published online: 24 April 2019 (C) The Author(s) 2019

\begin{abstract}
In modern polymer industry, there still is a room for new generations of fillers capable of enhancing the performance of composite materials. Currently, much effort is being put into a process of improving mechanical properties of elastomer materials. In this work, multiwalled carbon nanotubes (MWCNTs) and graphene nanoplatelets (GnPs) were modified with silane, titanate, or zirconate using plasma treatment, in order to apply them as fillers for styrene/butadiene rubber. Following its modification, filler surface was analyzed: Surface free energy (SFE) was measured with tensiometry, and micromorphology and chemical composition were studied with scanning electron microscopy-energy-dispersive spectroscopy (SEM-EDS), while elemental composition and bonding were assessed with X-ray photoelectron spectroscopy (XPS) and time-of-flight secondary ion mass spectrometry (ToFSIMS). Low-temperature oxygen plasma activation of MWCNT fillers leads to a significant increase in the SFE polar component, with the same effect being much weaker for GnP fillers. Grafting silanes, zirconates, and titanates on activated filler surface results in a decrease in SFE polar component-surface oxygen-containing active groups react with silane/zirconate/titanate molecules. Fillers modified in this way exhibit different micromorphology and surface chemical composition what is revealed with the SEM-EDS, ToF-SIMS, and XPS techniques. As the ultimate step, either MWCNT or GnP rubber nanocomposites were manufactured using the modified fillers with their mechanical properties and cross-link density being studied. Filler modification resulted in substantial changes both in composite performance, and in its cross-linking density. In the case of modified filler containing composites, improved tensile strength and elongation at break were observed.
\end{abstract}

Keywords Nanocomposites · Polymer - Carbon nanotubes · Plasma modification · Graphene nanoplatelets $\cdot$ Surface modification $\cdot$ Rubber

Mariusz Siciński

mariusz.sicinski@p.lodz.pl

Extended author information available on the last page of the article 


\section{Introduction}

Although the filler most commonly used in rubber technology is carbon black, in this dynamically developing industry, there is still a lot of room for new generations of carbon fillers that can improve performance or introduce novel functions to rubber vulcanizates. Due to their extraordinary properties and thanks to current prices that are much more acceptable than those of the last decade, such advanced powder fillers as carbon nanotubes (CNT) or graphene nanoplatelets $(\mathrm{GnP})$ are more and more often applied in the rubber industry. Since their discovery, these forms of carbon have focused scientific interest of research workers representing different fields [1]. Due to their unique mechanical, electrical, and thermal properties, CNTs and GnPs find themselves among the most promising candidates for fillers used in advanced rubber composites [2]. Unfortunately, as it has been quickly exposed, there is a major problem with their satisfactory dispersion in a rubber matrix.

A manufacture of high-quality rubber mixes requires certain degree of compatibility between the polymer matrix and the filler. It can only be achieved when, during the mixing process, filler particles remain in effective phase contact with rubber macromolecules. On the other hand, in order to improve a strengthening effect of the filler, a formation of large secondary filler structures should be avoided [3, 4] - especially when nanoparticles such as CNTs or GnPs are considered.

Modern polymer composite materials must be characterized with high performance, particularly in such demanding applications as aerospace or surface transportation (aircraft fuselages, vehicle tires). In order to meet these requirements, chemical industry keeps experimenting with ever more novel filler materials, capable of improving properties of the composites. There has been a real revolution in the polymer industry filler market taking place for the last two decades which, to a large extent, is due to an introduction of the so-called coupling agents. They are chemicals capable of compatibilizing surfaces of two phases of interest, namely filler surface and that of the polymer matrix, often substantially differing with their physical and chemical properties. The first coupling agents to be introduced in a mass production about 50 years ago were organosilane connections used to modify fiberglass. Approximately 20 years ago, organosilanes were first applied in the production of polymer composites filled with mineral fillers, such as kaolin, wollastonite, or mica. In this way, materials of an increased rigidity and improved dynamic properties were obtained. The aim of functionalized silane is an addition of its molecules to surface hydroxyl groups as a consequence of their hydrolysis. In this way, the organic part of silane is claimed to be exposed to the contact with polymer matrix, therefore improving phase compatibility, filler dispersion in the matrix and, consequently, properties of the composite.

A modern group of coupling agents is comprised of titanates and zirconates. They exhibit numerous advantages over silanes - they are more stable, contain more functional groups able to react with polymer matrix, and may be used practically with any type of a filler [5, 6]. Today, rubbers and composite materials 
manufactured with the use of titanate and zirconate coupling agents constitute a group of irreplaceable construction materials, mainly due to their excellent dynamic properties and ability to accept cyclic nondestructive deformations of high magnitudes. Phase boundary interactions between a polymer matrix and a filler have been constituting a subject of scientific interest for several decades. Nevertheless, it was not until 20 years ago that advanced surface modification methods appeared in the subject literature [7, 8]. The majority of reports concerned "wet" chemical modification of the fillers or other components of a composite. As far as such environment-friendly (practically producing no waste) methods as their low-temperature plasma treatment are concerned, there are hardly any publications found in the literature $[9,10]$.

To meet modern polymer industry requirements, surface free energy of the filler particles needs to be modified. Energetic compatibility of the rubber-filler system is a key to the success - too high SFE of the filler can adversely affect a distribution and intensify an agglomeration of its particles. In the case of carbon fillers, a potential to modify the SFE dispersive part is limited, so changes of rubber-filler interaction can rather be achieved by an adjustment of the polar component. One of the most often used methods of an activation of a carbon filler surface is comprised of its chemical solvent treatment. It generates covalently bonded functional groups [11]. As an effect of the treatment, the number of structural defects on the filler surface (e.g., CNTs sidewalls) increases, and various oxygen-containing functional groups are formed. The process is effective, but has a few serious drawbacks with the most severe being an application of large amounts of environmentally hazardous chemicals (usually a mix of sulfuric, nitric, and hydrochloric acid). Apart from oxidation, also halogenation, amination, alkylation, and an introduction of phenolic fragments to filler structure are being examined as wet modification techniques [12-14].

There are a number of reports in the literature dealing with a modification of multiwall carbon nanotubes (MWCNTs) for their application in nonpolar polymer matrix based composite materials $[15,16]$. The composites prepared in this way are characterized with extended strength, higher rigidity and often modified electrical properties [17]. Today, more and more frequent attempts to modify filler surface with alternative methods are being made. One such method is low-temperature plasma treatment. Since it is a gas-phase technique, it has no drawbacks characteristic for the solvent-based methods. An application of plasma techniques is particularly promising from the point of view of a modern polymer technology, especially due to environment protection issues-plasma treatment does not generate waste, and it is fast and economically effective.

Low-temperature plasma can be generated with an electrical discharge taking place in a low-pressure reactor chamber. The discharge is maintained in the presence of a gas, such as $\mathrm{Ar}, \mathrm{O}_{2}, \mathrm{H}_{2}, \mathrm{~N}_{2}$, acetylene, methane, or simply air. Depending on the type of the gas used and the process operational parameters, plasma treatment can be applied either for cleaning the material surface (so-called microsandblasting), for grafting functional groups via reaction of the surface with ionized gas particles, or for thin-film formation on that surface. For different 
materials and purposes, a variety of generator frequencies can be applied-beginning from audio frequency up to microwave range.

Plasma processing also appears to be an effective method of CNT purificationan amorphous carbon layer is eliminated during that process [18]. According to Xu et al., the modification process undergoes four-stage mechanism (see Fig. 1):

Stage 1 Plasma irradiation, expansion of amorphous carbon layer, and beginning of its elimination occur, and oxygen concentration increases.

Stage 2 Ion bombardment causes creation of vacancies and interstitials ( $s p^{3}$ structure is much weaker than $s p^{2}$ ), and oxygen concentration increases.

Stage 3 Ion bombardment continues until amorphous layer is totally peeled from carbon nanotubes, and oxygen concentration increases.

Stage 4 Amorphous carbon is oxidized and ultimately eliminated when material is treated for a long enough period of time.

Our previous studies have shown that in the case of carbon nanotubes lowtemperature plasma treatment introduces changes to surface free energy and its components [19]. In the past years, several attempts were made to adapt lowtemperature plasma to the modification of filler surface [20-35]. However, there is general lack of work reporting an application of this technique to plasma grafting of coupling agents on the surface of MWCNT filler. The present work reports results of low-temperature plasma modification of two types of carbon
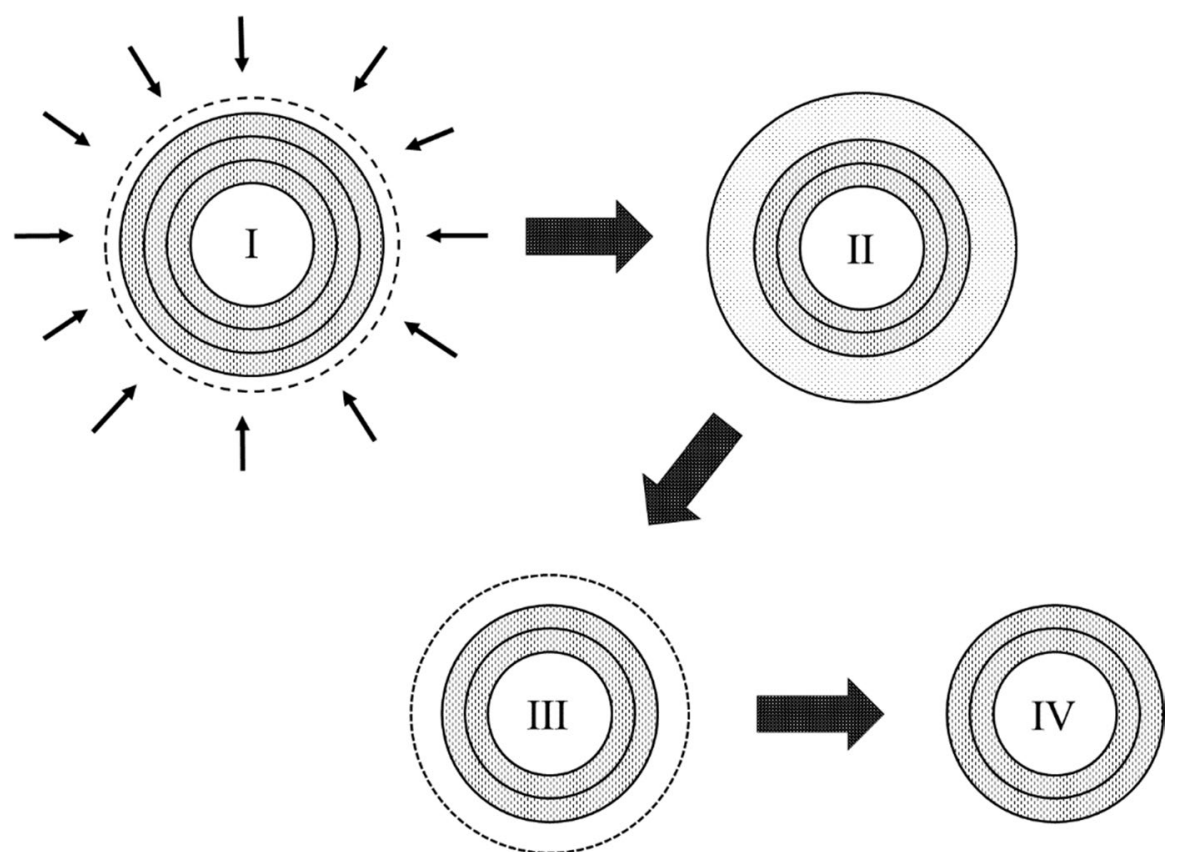

Fig. 1 Mechanism of oxygen plasma treatment of MWCNT [18] 
filler, namely multiwall carbon nanotubes (MWCNTs) and graphene nanoplatelets (GnPs), that are later used to manufacture a styrene/butadiene rubber vulcanizate. The modification process is performed in two stages: First, filler surface activation is carried out in oxygen plasma, and it is then followed by grafting silane, titanate, and zirconate functions on that surface. This approach is powered by new possibilities and perspectives for applications of CNT containing composites, among others in the modern tire industry.

\section{Experimental details}

\section{Materials}

- KER 1500 styrene-butadiene rubber manufactured by Synthos, Poland, was used as rubber matrix.

- When it comes to fillers, the following carbon forms were applied:

- either multiwalled carbon nanotubes (MWCNT) of $98 \%$ purity made by Cheaptubes (USA),

- or graphene nanoplatellets (GnP) Grade $3.95 \%$ purity manufactured by Cheaptubes (USA).

As far chemicals for low-temperature plasma modification of filler surfaces are concerned, there were three categories of compounds used in this work. One was silanes, and namely either vinyltrimethoxysilane (VTMS) of 99\% purity or mercaptotrimethoxysilane (MTMS) of $99 \%$ purity, both made by Sigma-Aldrich, USA. Structural formulas of silane modifiers are presented in Fig. 2.

The second category of grafting chemicals was comprised either of titanates or of zirconates, all manufactured by Kenrich Petrochemicals USA, and shown in Figs. 3 and 4. In particular, these compounds were: NZ 33 Zirconium IV 2,2(bis2-propenolatomethyl)butanolato, tris 2-methyl-2-propenoato-O, and-NZ 01 Zirconium IV 2,2(bis-2-propenolatomethyl)butanolato, tris neodecanolato-O presented in Fig. 3, and KR TTS Titanium IV 2-propanolato, tris isooctadecanoato$\mathrm{O}$, and KR 33DS Titanium IV, tris(2-methyl)-2-propenoato-O, methoxydiglycolylato presented in Fig. 4.

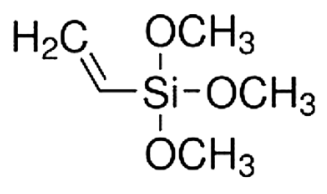

(a)

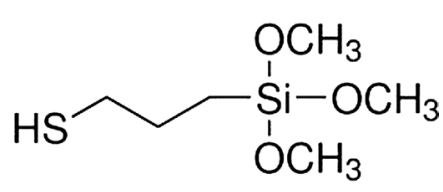

(b)

Fig. 2 Structures of silane compounds used as grafting agents during CNT and GnP surface modification: vinyltrimethoxysilane (a) and mercaptotrimethoxysilane (b) 
<smiles>C=CCOC(CC)(CO[Te](OC(=O)C(=C)C)(OC(=O)C(=C)C)OC(=O)C(=C)C)OCC=C</smiles>

(a)

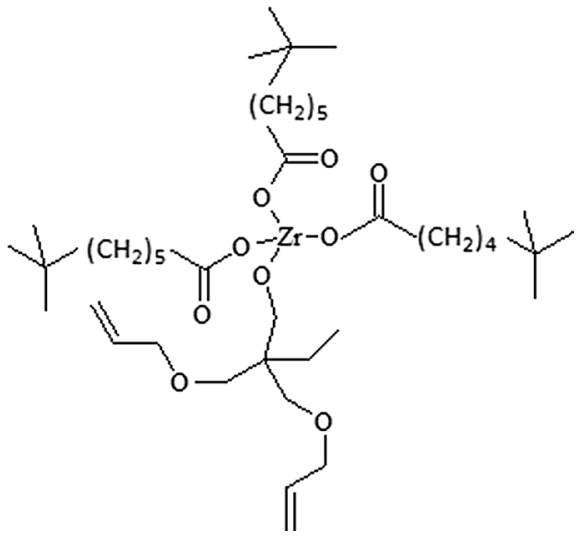

(b)

Fig. 3 Structures of zirconate compounds used as grafting agents during CNT and GnP surface modification: NZ 33 Zirconium IV 2,2(bis-2-propenolatomethyl) butanolato, tris 2-methyl-2-propenoato-O (a), and NZ 01 Zirconium IV 2,2(bis-2-propenolatomethyl)butanolato, tris neodecanolato-O (b)

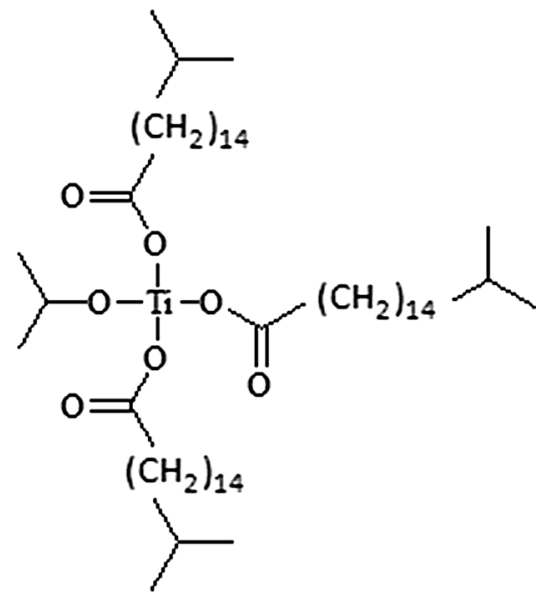

(a)<smiles></smiles>

(b)

Fig. 4 Structures of titanate compounds used as grafting agents during CNT and GnP surface modification: KR TTS Titanium IV 2-propanolato, tris isooctadecanoato-O (a), and KR 33DS Titanium IV, tris(2methyl)-2-propenoato-O, methoxydiglycolylato (b)

\section{Low-temperature plasma treatment}

Plasma treatment was conducted in a Diener (Germany), model Zepto reactor operated at $40 \mathrm{kHz}$ and equipped with a tumbling chamber of $1.5 \mathrm{dm}^{3}$ capacity. The maximum applied discharge power was equal $100 \mathrm{~W}$. Schematic representation of the reactor is shown in Fig. 5. 


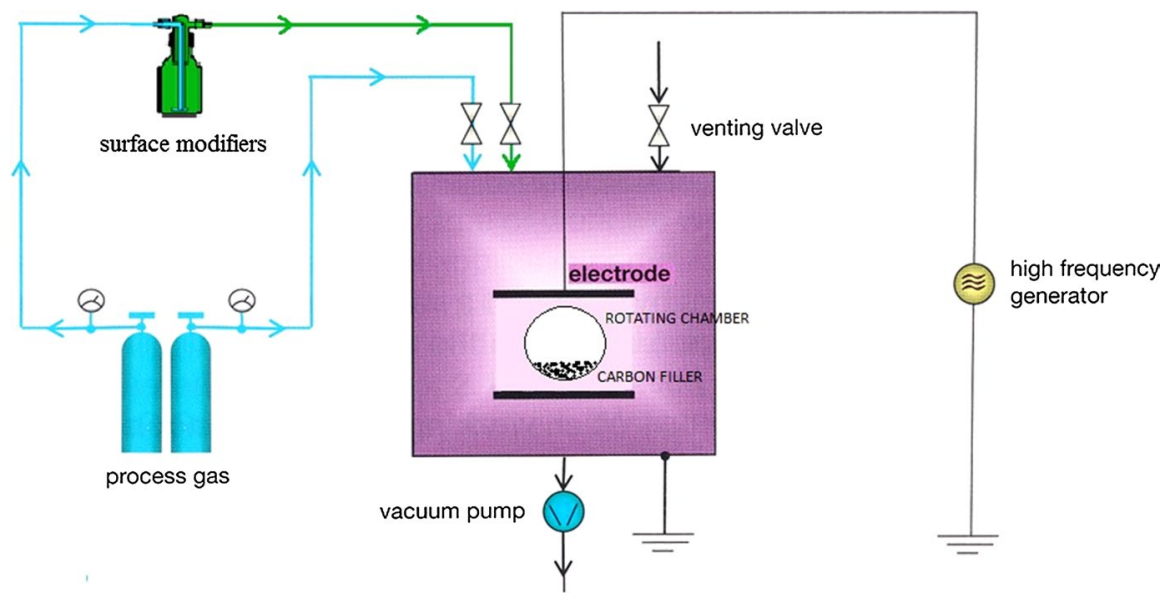

Fig. 5 Schematic representation of the plasma reactor used

An activation of the filler surface was conducted in oxygen plasma, with process operational parameters being discharge power and its duration time. Chamber pressure amounted to $30 \mathrm{~Pa}$ and the process gas flow rate was maintained at the level of $30 \mathrm{sccm}$. Following oxygen plasma activation of the fillers $(8-48 \mathrm{~min})$, one of the silane/titanate/zirconate surface modifiers was introduced (in a form of vapor) into a reactor chamber for $30 \mathrm{~min}$ with its flow rate remaining at $20 \mathrm{sccm}$.

\section{Preparation of rubber mixes}

Carbon fillers plasma modified with the help of the above procedures were then used to prepare rubber mixes and to manufacture respective vulcanizates. A Brabender (Germany) model Plasticorder laboratory micromixer was applied for that purpose. The time of preparation was $30 \mathrm{~min}$ with the rotational rate of $45 \mathrm{rpm}$. A composition of the samples is presented in Table 1.

Table 1 A composition of the rubber mixes studied

\begin{tabular}{ll}
\hline Component & Content [phr] \\
\hline SBR KER1500 & 100 \\
Filler & 5 \\
ZnO & 3.5 \\
Stearine & 1 \\
CBS & 2 \\
Sulfur & 2 \\
TMTD & 0.2 \\
CNT & 5 \\
\hline
\end{tabular}




\section{An assessment of surface free energy}

Changes of the surface free energy (SFE), as well as those of its polar and dispersive components were measured with the help of a KRÜSS GmbH (Germany), model K100 MKII tensiometer. The values of contact angle were determined using both polar (water, methanol, ethanol) and nonpolar ( $n$-hexane, $n$-heptane) liquids. As the final step of the assessment, magnitudes of SFE and its components were calculated by applying the Owens-Wendt-Rabel-Kaeble formalism [36].

\section{Vulcanization procedure}

The parameters of vulcanization such as maximum $\left(M_{\max }\right)$ and minimum $\left(M_{\min }\right)$ torque, a difference between minimum and maximum torque $(\Delta M)$, and vulcanization time ( $t 90)$ were determined with the help of a Monsanto (USA) model R100 rheometer, at the temperature of $160{ }^{\circ} \mathrm{C}$, in accordance with the ISO 3417 standard.

\section{Mechanical properties of rubber vulcanizates}

Mechanical properties of the vulcanizates were determined using a Zwick 1435 (Germany) universal mechanical testing machine. The tests were carried out on "dumbbell"-shaped 2-mm-thick and 4-mm-wide specimens, in accordance with the ISO 37 standard. In particular, elongation at break (Eb), stress at 100\% elongation (M100), and tensile strength (TS) were determined.

\section{Cross-link density of rubber vulcanizates}

Cross-link density of rubber vulcanizates was determined using experimental results of their $72 \mathrm{~h}$ equilibrium swelling in toluene, with an application of the Flory formula (1) [37]:

$$
v=-\frac{1}{V_{0}} \cdot \frac{\ln \left(1-V_{\mathrm{r}}\right)+V_{\mathrm{r}}+\mu V_{\mathrm{r}}^{2}}{\sqrt[3]{V_{\mathrm{r}}}-\frac{2 V_{\mathrm{r}}}{f}},
$$

where $v$ denotes cross-link density $\left[\mathrm{mol} / \mathrm{cm}^{3}\right] ; V_{0}$ denotes solvent molar volume in a swollen sample; $V_{\mathrm{r}}$ denotes rubber volume in a swollen sample; $f$ denotes functionality of cross-linking $(f=4) ; \mu$ denotes Huggins parameter.

\section{Micromechanical properties (nanoindentation)}

The micromechanical properties of rubber vulcanizates were determined with the help of Micromaterials Ltd. (UK), model NanoTest600 apparatus equipped with a Berkovich indenter. The following were the measurement parameters: max depth of $3500 \mathrm{~nm}$, unloading speed $\mathrm{d} P / \mathrm{d} T=0.05 \mathrm{mN} / \mathrm{s}$. Measurements were carried 
out under controlled atmosphere with its temperature equal $25 \pm 2{ }^{\circ} \mathrm{C}$ and relative humidity of $60 \pm 5 \%$. The calculation procedure was based on the Olivier and Pharr method [38].

\section{Time-of-flight secondary ion mass spectrometry (SIMS)}

ToF-SIMS measurements were performed using an ION-TOF GmbH (Germany) model TOF-SIMS IV instrument equipped with a $25-\mathrm{kV}$ pulsed $\mathrm{Bi}^{+}$primary ion gun operating in a static mode. The filler samples were pressed into the indium plate and attached to the sample holder using a double-sided tape. For each sample, three spectra collected at various locations were recorded. The analyzed area corresponded to a square of $500 \mu \mathrm{m} \times 500 \mu \mathrm{m}$ size. A pulsed electron flood gun was used for the charge compensation.

\section{Scanning electron microscopy (SEM)}

Filler microstructure in a rubber matrix was studied with a Zeiss (Germany) model Auriga scanning electron microscope. A secondary electron signal was analyzed, as well as signals from energy-selective backscattered detector (ESB) and energy-dispersive detector (EDS). Accelerating voltage applied was $10 \mathrm{keV}$.

\section{Filler dispersion in rubber composite}

An analysis of filler dispersion in the rubber composite was performed with the Montech (USA) model DisperTester 3000 apparatus working in accordance with the ISO 11345:2006 standard. The instrument's precision telecentric optical system makes use of reflected light for obtaining high-resolution reflective images of the sample surface. Data processing was carried out with the help of MonDispersion software, delivered with the instrument. Magnification applied was $\times 1000$, with all the images referring to an area of $250 \times 150 \mu \mathrm{m}$.

\section{X-ray photoelectron spectroscopy (XPS)}

The XPS measurements were carried out with the help of a Kratos AXIS Ultra XPS spectrometer using monochromatic $\mathrm{Al} \mathrm{K} \alpha$ X-rays source of an excitation energy of $1486.6 \mathrm{eV}$. The spectra were obtained from an area of $300 \mu \mathrm{m} \times 700 \mu \mathrm{m}$. The power of anode was set at $150 \mathrm{~W}$, and the hemispherical electron energy analyzer was operated at a pass energy $20 \mathrm{eV}$ for all the high-resolution measurements. All measurements were performed with the use of a charge neutralizer, and every spectrum recording was repeated 10 times in order to increase its signal-to-noise ratio. Evaluation of XPS data was conducted using a Kratos Vision 2 software. 


\section{Results and discussion}

\section{Plasma activation of filler surface}

Both types of fillers, namely multiwalled carbon nanotubes and graphene nanoplatellets, were subjected to oxygen plasma activation of their surface. The activation efficiency was then assessed with the measurements of surface free energy as well as both its components: dispersive and polar. As far as filler containing vulcanizates are concerned, mechanical properties were used as a measure of their performance.

\section{Carbon nanotubes}

Results of SFE measurements of carbon nanotubes are presented in Fig. 6. As seen in the figure, the nanotubes were found to be susceptible to oxygen plasma activation. Surprisingly, however, a reference sample (MWCNTs before treatment) also exhibited a substantially high SFE polar component, what could be attributed to a partial oxidization of a residual amorphous carbon layer. The modification mechanism seems to be similar to that described by Xu et al.--initially an amorphous layer is removed, and material slightly expands [10]. In the next stage, grafting of oxygencontaining groups begins, what is reflected by a significant increase in a SFE polar component. The maximum of SFE was attained after $32 \mathrm{~min}$ of activation $(28.1 \mathrm{~mJ} /$ $\mathrm{m}^{2}$ ) with an intermediate value of $25.5 \mathrm{~mJ} / \mathrm{m}^{2}$ acquired for $16 \mathrm{~min}$ activation. After 8 min of oxygen treatment, SFE value is lower than that for a reference sample (20.9 compared to $22.6 \mathrm{~mJ} / \mathrm{m}^{2}$ ), which confirms a notion that a surface cleaning process constitutes the first stage of the treatment. All changes of the surface free energy are caused by an increase in its polar component, which reaches the value of $9.8 \mathrm{~mJ} / \mathrm{m}^{2}$

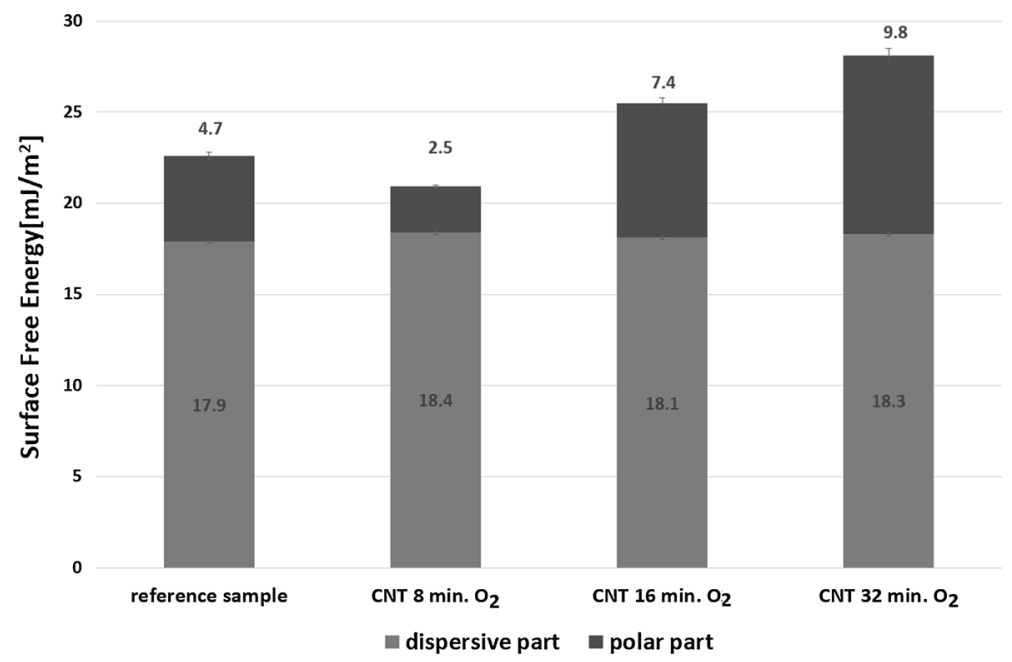

Fig. 6 Surface free energy and its components of the activated MWCNT fillers 
after 32 min of modification. It means that a substantial amount of oxygen-containing polar groups have been formed on the CNT's sidewalls.

\section{Graphene nanoplatellets}

SFE results of oxygen plasma modification of graphene nanoplatellets are presented in Fig. 7. As indicated in the figure, GnPs are significantly less susceptible to the activation than carbon nanotubes shown in Fig. 6. This is very likely due to their more stable structure ( $s p^{2}$ carbon hybridization). Also in this case, a reference sample seems to be initially slightly oxidized (see Fig. 7). The effect of plasma treatment on surface energy is rather mediocre - a maximum SFE value obtained for modified GnPs was $22.6 \mathrm{~mJ} / \mathrm{m}^{2}$, and it was only reached after $48 \mathrm{~min}$ of modification. Modification processes shorter than that do not affect surface energy of graphene nanoplatellets-SFE neither changes as a whole, nor do its polar and dispersive components.

\section{Mechanical properties of rubber composites containing activated carbon fillers}

Microhardness and plastic deformation results of rubber composites containing oxygen plasma-activated carbon fillers are presented in Table 2. As seen in the table, microhardness represents the highest values for vulcanizates filled with CNTs and GnPs activated for $32 \mathrm{~min}$ and for $48 \mathrm{~min}$, respectively. Extending the modification time leads to a decrease in microhardness. Plastic deformation of the surface layer determined in this test appears to be inversely proportional to the microhardness values.

The effect of filler activation is also reflected by changes of other mechanical properties of rubber vulcanizates, such as mean $100 \%$ elongation modulus, known as M100, tensile strength, and elongation at break. Results of the respective

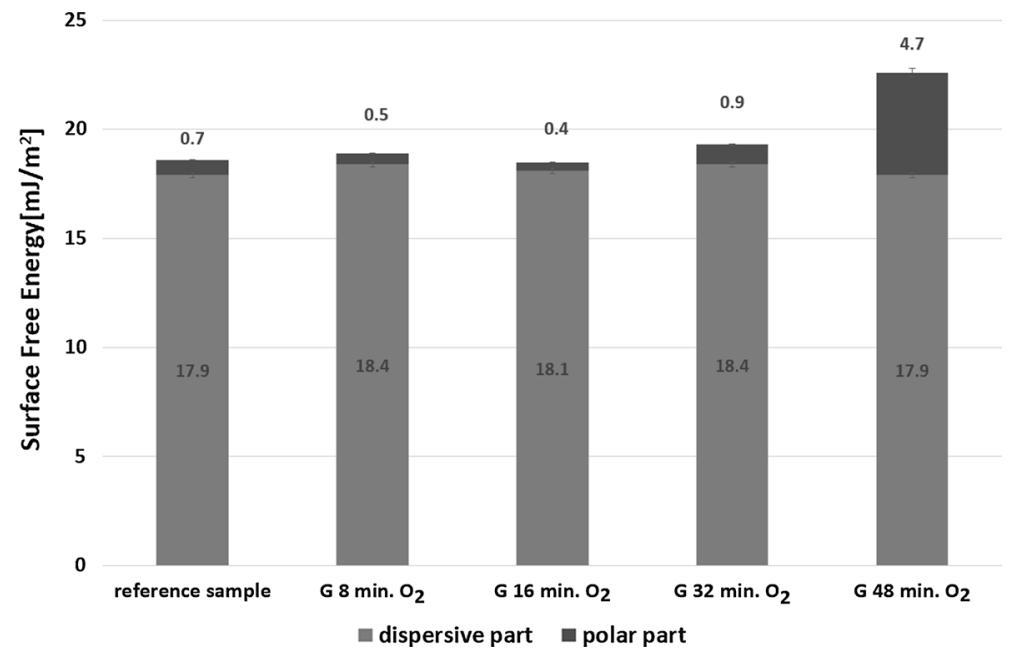

Fig. 7 Surface free energy and its components of activated GnP fillers 
Table 2 Micromechanical properties of the rubber vulcanizates containing oxygen plasma-activated carbon fillers

\begin{tabular}{lll}
\hline & Microhardness [MPa] & $\begin{array}{l}\text { Plastic defor- } \\
\text { mation }[\mu \mathrm{m}]\end{array}$ \\
\hline $\mathrm{SBR} / \mathrm{CNT}_{0}$ & $2.6 \pm 0.1$ & $2.9 \pm 0.3$ \\
$\mathrm{SBR} / \mathrm{CNT}_{16}$ & $3.1 \pm 0.1$ & $2.6 \pm 0.2$ \\
$\mathrm{SBR} / \mathrm{CNT}_{32}$ & $4.5 \pm 0.1$ & $2.2 \pm 0.2$ \\
$\mathrm{SBR} / \mathrm{GnP}_{0}$ & $3.2 \pm 0.1$ & $2.6 \pm 0.4$ \\
$\mathrm{SBR} / \mathrm{GnP}_{8}$ & $4.1 \pm 0.1$ & $2.3 \pm 0.2$ \\
$\mathrm{SBR} / \mathrm{GnP}_{16}$ & $2.3 \pm 0.1$ & $3.1 \pm 0.5$ \\
$\mathrm{SBR} / \mathrm{GnP}_{32}$ & $3.1 \pm 0.1$ & $2.6 \pm 0.2$ \\
$\mathrm{SBR} / \mathrm{GnP}_{48}$ & $5.7 \pm 0.1$ & $1.9 \pm 0.1$ \\
\hline
\end{tabular}

measurements for rubber composites filled with activated carbon nanotubes are presented in Fig. 8. As seen in the figure, composite performance does not alter when the polymer matrix is filled with a filler exhibiting no changes of its surface free energy due to plasma treatment. On the other hand, the sample filled with MWCNTs activated for $32 \mathrm{~min}$ is much stiffer than a reference sample-its M100\% amounts to 1.46 MPa compared to 1.23 MPa for the reference. Tensile strength of that sample is also substantially higher, with its mean value amounting to $8.80 \mathrm{MPa}$ compared to $6.87 \mathrm{MPa}$ for the reference sample. Finally, its mean value of elongation at break equals $1044 \%$ as opposed to $842 \%$ for the reference.

An important factor affecting mechanical properties of the composites appears to be filler microstructure, which changes for oxidized MWCNTs-expanded material is less bundled [9], and it can be incorporated more uniformly into the rubber

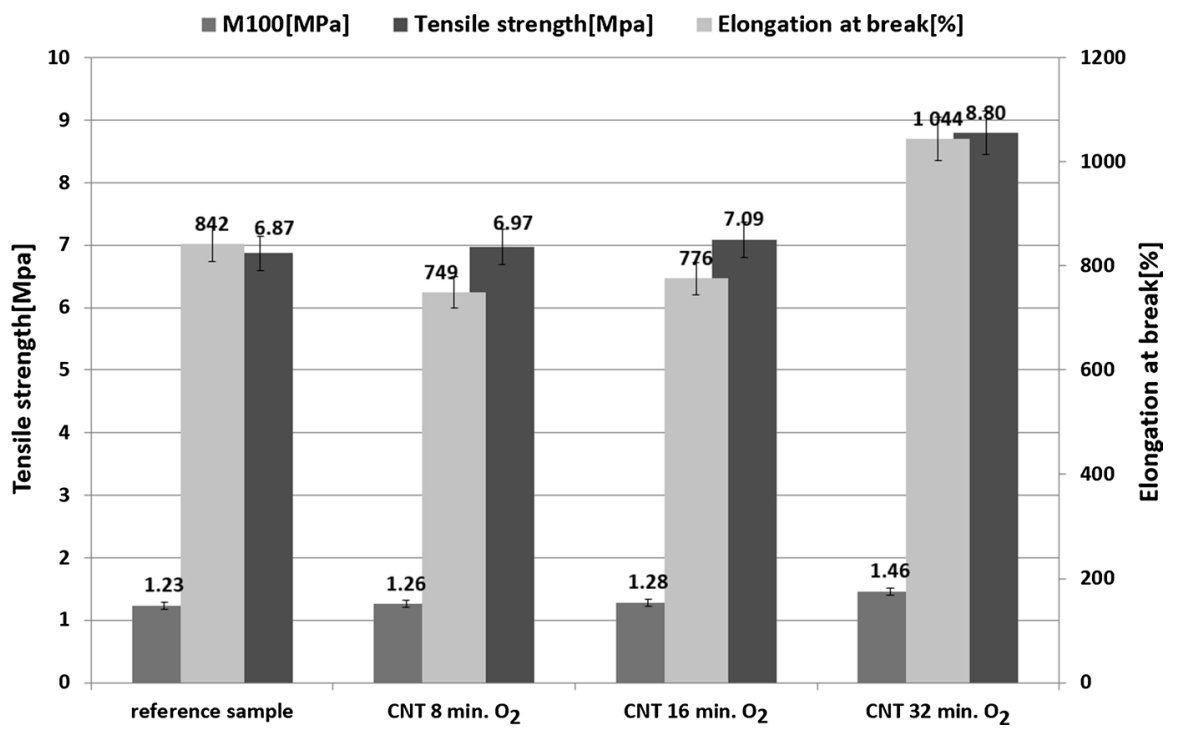

Fig. 8 Mechanical properties of the SBR/MWCNT vulcanizates 
matrix. Apparently, an energetic effect may also play a significant role-if modified filler exhibits SFE values higher than or close to that of polymer matrix (29-33 mJ/ $\mathrm{m}^{2}$ for SBR), than the expected interfacial interactions should be more intensive.

As far as rubber composites filled with graphene platelets are concerned, only slight differences in their mechanical properties were observed as a result of filler activation. The respective data are presented in Fig. 9. As seen in the figure, $48 \mathrm{~min}$ of oxygen plasma treatment of $\mathrm{GnP}$ fillers caused an increase in mean tensile strength value of therewith filled rubber vulcanizates from 5.13 to $5.56 \mathrm{MPa}$ only, while their mean $100 \%$ elongation modulus changed from 1.13 to $1.32 \mathrm{MPa}$. Elongation at break neither changed significantly, remaining the level of 744-787\%. The changes in composites performance are probably caused by $\mathrm{GnP}$ surface cleaning effects, without a major influence on SFE values and minor interfacial performance improvement. Very likely, the microstructure of the filler also changes in this case, and some graphene galleries are exfoliated, thus increasing the surface area available for rubber macromolecules [9].

\section{Activated filler modification with silane derivatives}

For further studies, 48-min GnP and 32-min MWCNT oxygen plasma-activated samples were selected, as materials characterized by the highest amounts of surface active centers and oxygen-containing groups. The second step of a filler modification was comprised of the exposure of its activated surface to the discharge maintained in the vapors of one of the two different silane derivatives, either vinyltrimethoxysilane

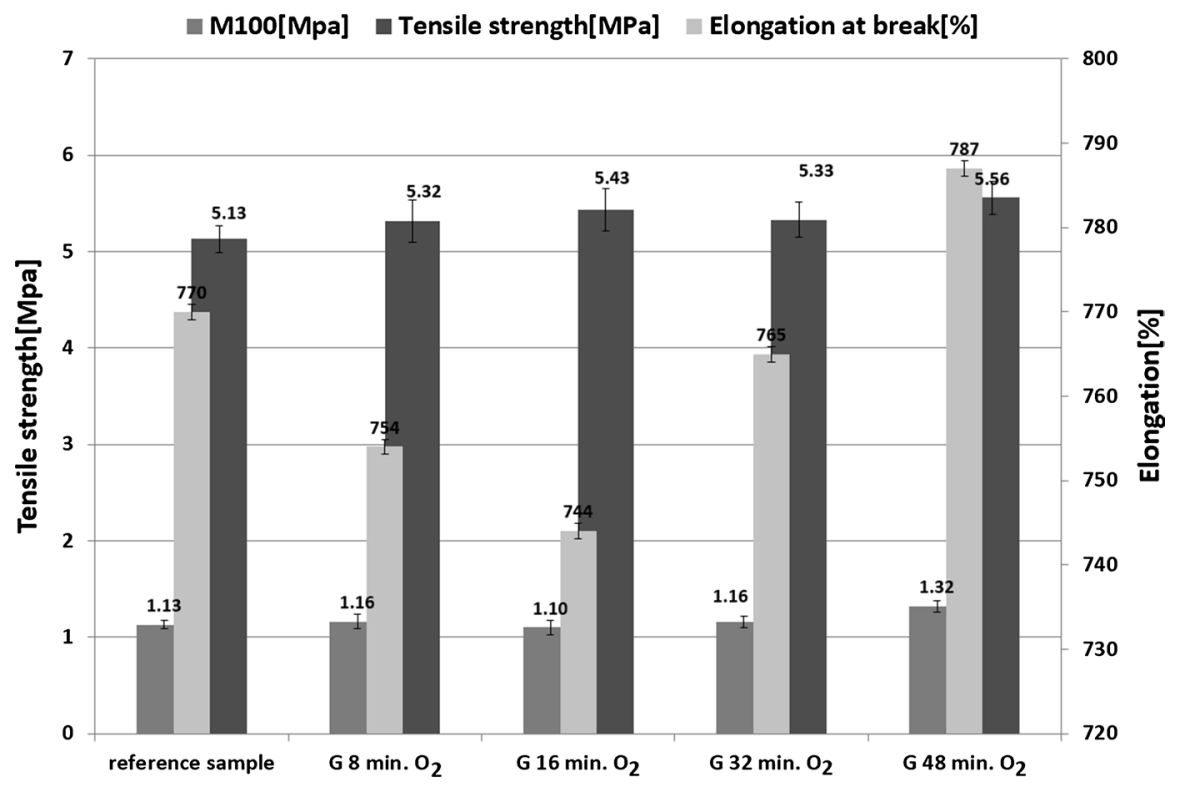

Fig. 9 Mechanical properties of the SBR/GnP vulcanizates 


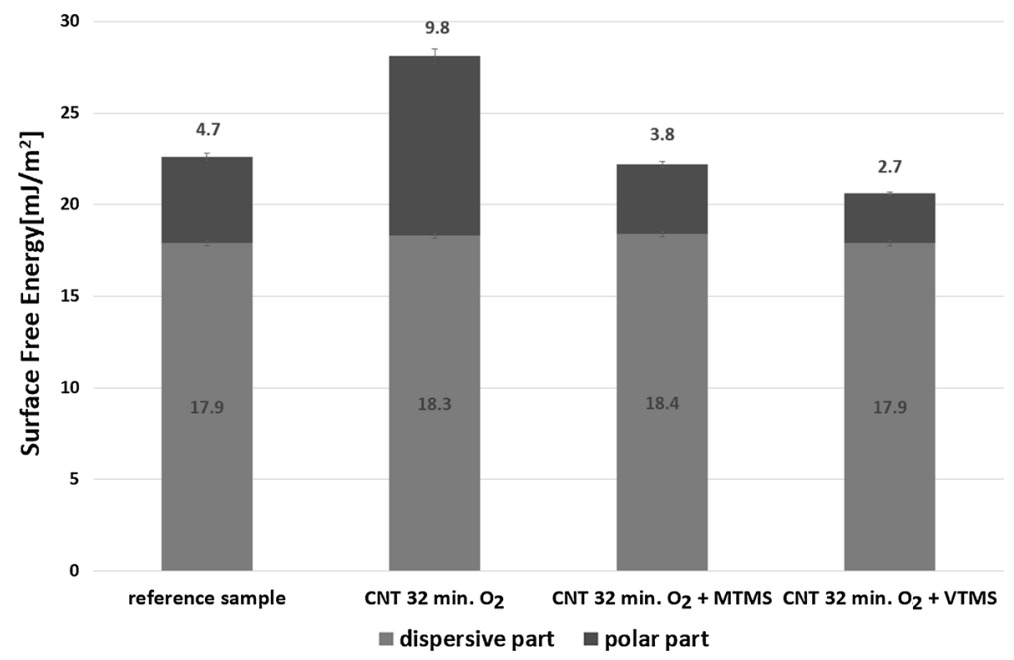

Fig. 10 Surface free energy and its components of silane-modified MWCNTs

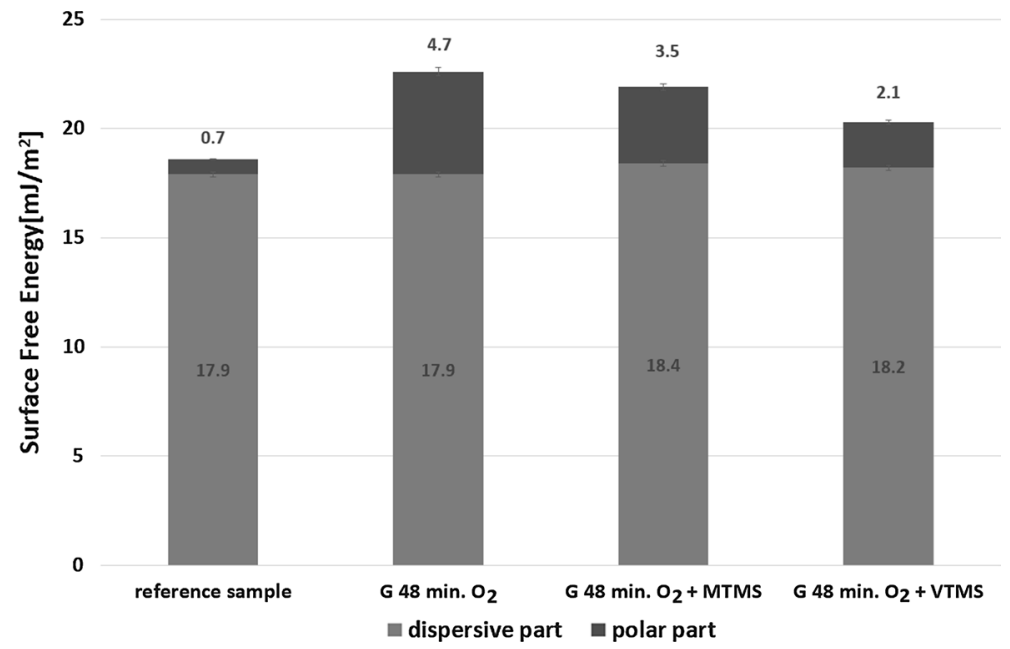

Fig. 11 Surface free energy and its components of silane-modified GnPs

or mercaptotrimethoxysilane. It was expected that the hydroxyl groups formed after silane hydrolysis would react with active polar groups present on filler's surface, thus exposing vinyl (VTMS) or thiol (MTMS) functions to interactions with the rubber macromolecule. These interactions, together with material surface cleaning effect, were anticipated to increase the compatibility of filler-matrix system and additionally to be involved in the cross-linking process.

The effect of additional filler modification with silane derivatives is presented in Figs. 10 and 11 for GnP and MWCNT fillers, respectively. As seen in the figures, 
this effect is very similar for both kinds of the filler-in both instances the modification leads to a decrease in the polar component of SFE. This is a likely effect of a condensation of hydroxyl groups, as well as that of silane reaction with radical active centers and structural defects generated in the plasma discharge. Active centers available and oxygen-containing groups generated in plasma are grafted with silane molecules, with their vinyl (in the case of VTMS) or thiol (in the case of MTMS) groups remaining exposed and, therefore, available for interactions with rubber macromolecules. In both cases, i.e., for GnP and for MWCNT fillers, one can observe the same trend in differences between silane derivatives-after grafting MTMS the SFE polar component is higher than for VTMS, what can be explained by higher polarity of the thiol group.

In the case of silane-grafted MWCNTs, the SEM-EDS-ESB analysis was carried out in order to study their micromorphology as well as elemental composition. Figure 12 presents images of VTMS-modified filler (c-f) and those of unmodified carbon nanotubes $(a, b)$ as a reference.

In the above figure, one can observe the mass contrast (Fig. 12b, d) between carbon filler and silicon originating from VTMS-grafted moieties, with bright areas indicating the presence of $\mathrm{Si}$ atoms. It is clear from the figure that silicon is not present in the reference sample (Fig. 12b), while there is a lot of signal originating from this element in the case of VTMS-grafted MWCNTs (Fig. 12d). This finding confirms the effectiveness of vinyltrimethoxysilane grafting on MWCNT surfaces. In Fig. 12e, f, one can see images of a single nanotube with a VTMS particle grafted.

Figure 13 presents a general element EDS spectrum of a VTMS-modified MWCNT sample. As seen in the figure, several signals are present-carbon, oxygen coming from filler activation, $\mathrm{Ni}$ as a residue of MWCNT synthesis catalyst, and $\mathrm{Si}$ from VTMS modification.

Time-of-flight secondary ion mass spectrometry spectra of sulfur ion concentration for reference and mercaptotrimethoxysilane-modified MWCNT samples are presented in Fig. 14. As seen in the figure, significant differences are recorded between both samples. In the case of a MTMS-modified specimen, thiol group-containing silane delivers sulfur atoms to the filler surface, what confirms the effect of MWCNTs surface modification with MTMS plasma.

An XPS analysis was performed in the case of non-modified MWCNTs and those modified with vinyltrimetoxysilane. Quantitative results of that analysis, presented in Table 3, show that the modification increases the amount of oxygen present on the surface of the carbon material. The presence of silicon at the nanotube surface, on the other hand, points to the effectiveness of the modification process.

In the sample modified with VTMS, a surface content of silicon amounts to ca. 10.6 at.\%. As seen in Table 3, non-modified nanotubes contain substantially lower amount of oxygen on their surface than the surface concentration of this element recorded for the filler modified with vinyltrimetoxysilane and amounting to 29.3 at.\%. This result is also higher than oxygen content in a VTMS molecule, which is a consequence of high silicon affinity toward oxygen on the one hand, and a substantial fragmentation of vinyltrimetoxysilane under plasma conditions, on the other.

Figure 15 shows examples of XPS survey spectra of the surfaces of: nonmodified MWCNTs (a) and those modified with VTMS (b). A calibration of 


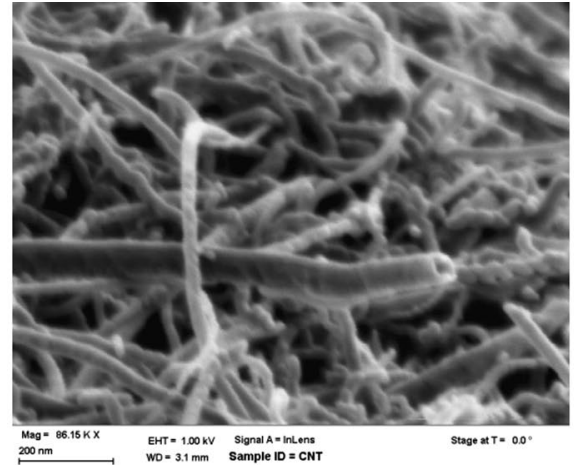

(a)

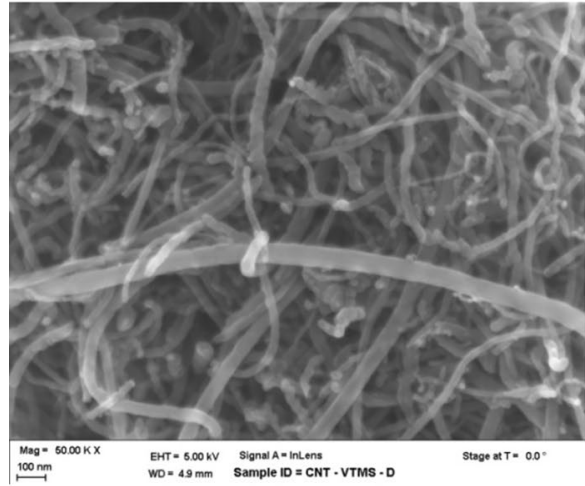

(c)

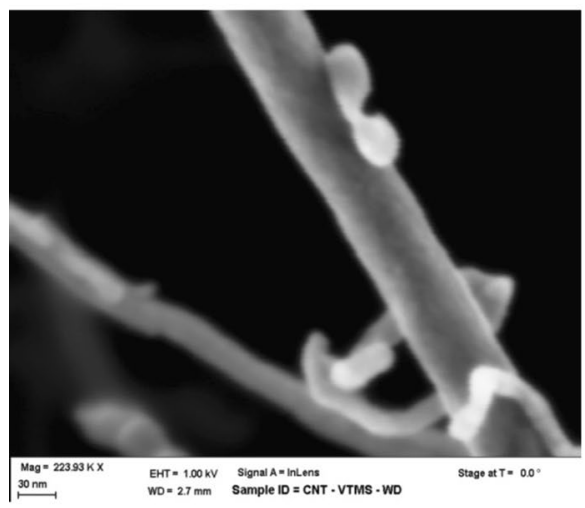

(e)

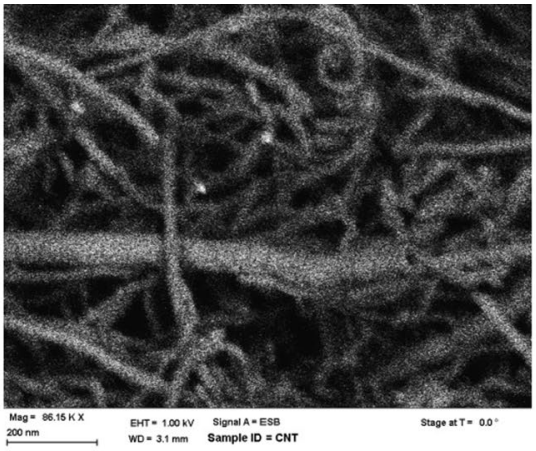

(b)

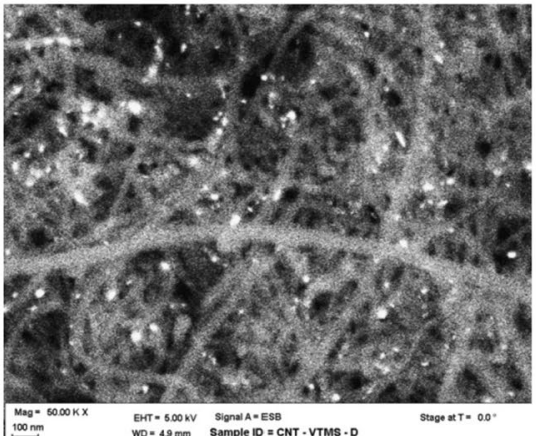

(d)

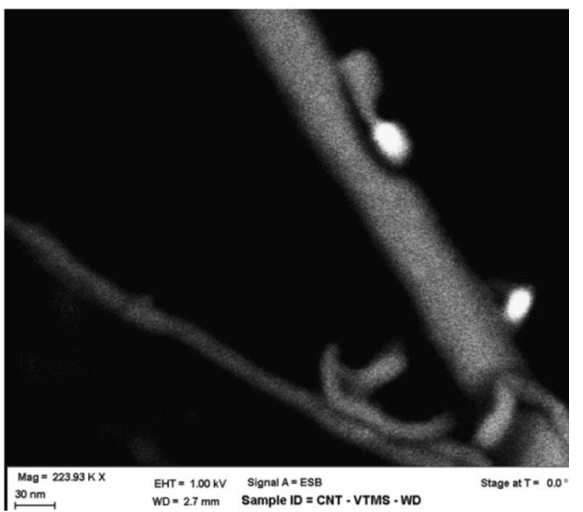

(f)

Fig. 12 SEM micrographs of the MWCNT filler: micromorphology of a reference MWCNT sample (a), mass contrast image (ESB detector) of a reference sample (b), micromorphology of VTMS-modified MWCNTs (c), mass contrast image of VTMS-modified MWCNTs (d), micromorphology of a VTMSmodified single MWCNT (e), mass contrast image of a VTMS particle grafted on a single MWCNT (f) 


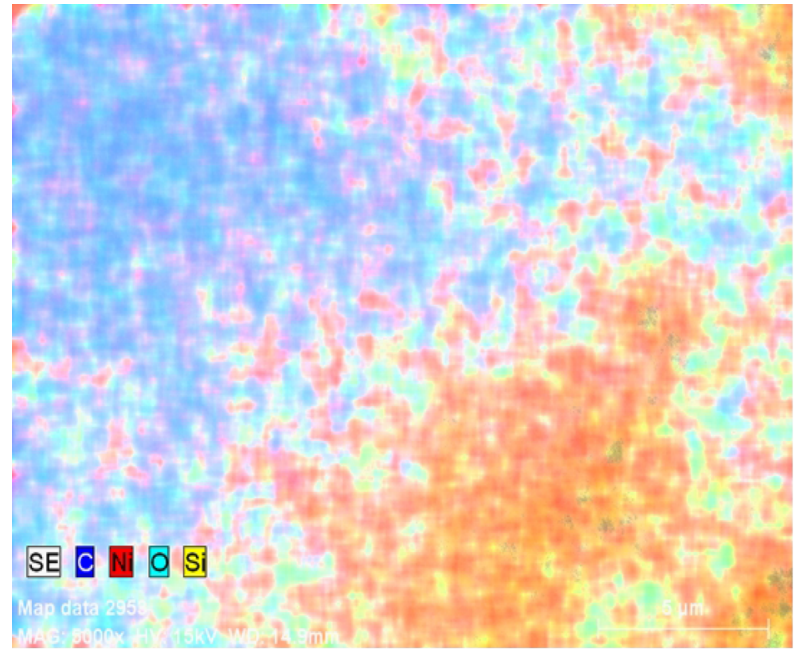

(a)

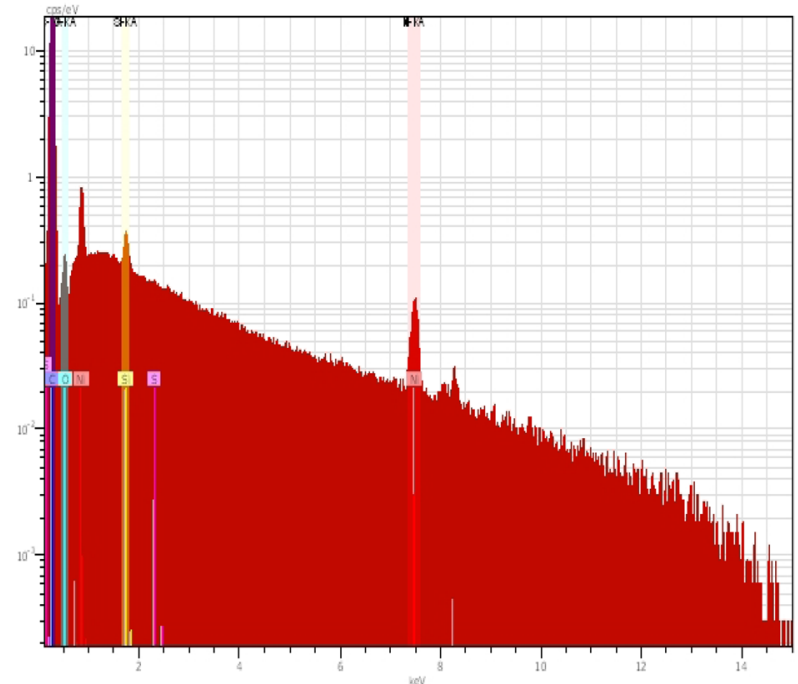

(b)

Fig. 13 SEM-EDS image of VTMS-modified MWCNT surface (a), elementary SEM-EDS spectrum of VTMS-modified MWCNTs (b)

these spectra was performed on the basis of a maximum at the binding energy of $286.4 \mathrm{eV}$ corresponding to $s p^{2}(\mathrm{C}=\mathrm{C})$ bonds. There are following bands present in the spectrum of non-modified WMCNTs: C $1 s$ at ca. $284.6 \mathrm{eV}, \mathrm{O} 1 s$ at ca. $532.1 \mathrm{eV}$, and $\mathrm{O} 2 s$ at ca. $28.5 \mathrm{eV}$. Finally, in the XPS spectrum of nanotubes modified with VTMS, two silicon bands appear: a Si $2 s$ band at approximately $154.2 \mathrm{eV}$ and a Si $2 p$ band at approximately $102.9 \mathrm{eV}$. Out of all these bands, the 


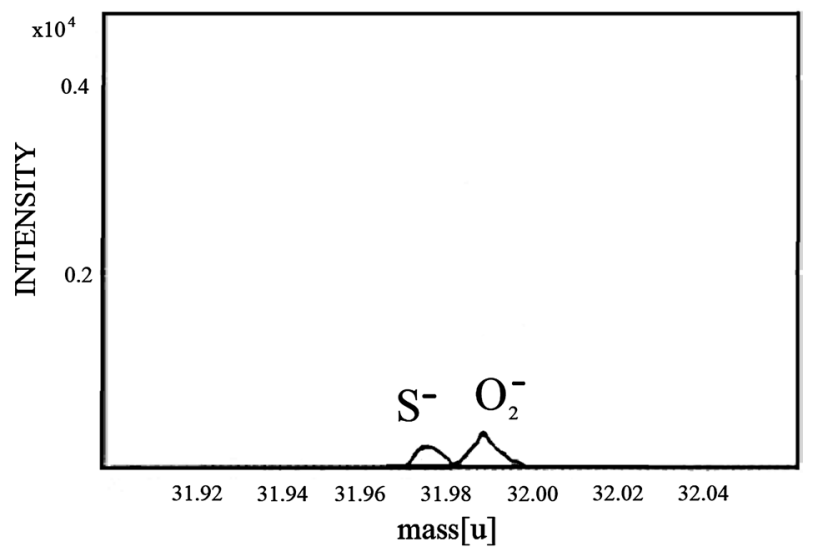

(a)

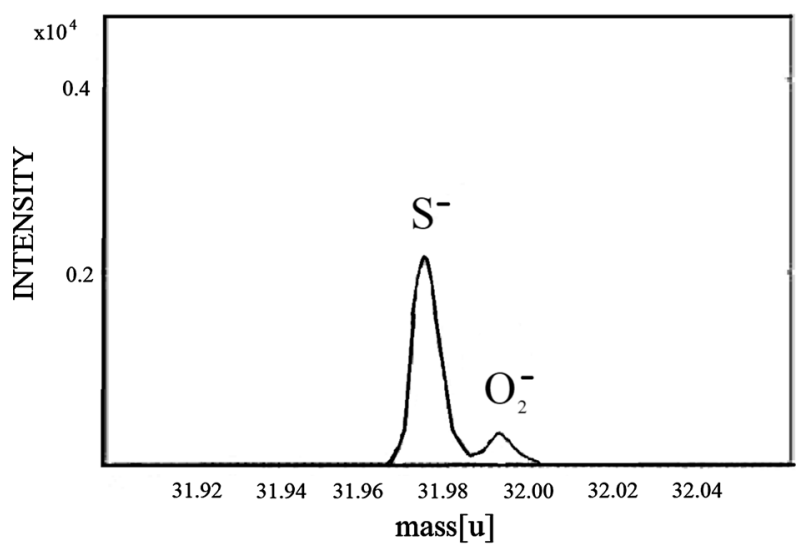

(b)

Fig. 14 Fragments of specific ToF-SIMS spectra indicating a presence of sulfur ions: reference MWCNT sample (a), MTMS-modified MWCNT sample (b)

Table 3 XPS data of surface elemental composition of nanotube samples

\begin{tabular}{llll}
\hline Type of modifier & \multicolumn{4}{l}{ Atomic composition of the films [at.\%] } \\
\cline { 2 - 4 } & $\mathrm{C}$ & $\mathrm{O}$ & $\mathrm{Si}$ \\
\hline 00 & $83.8 \pm 1.60$ & $16.2 \pm 0.6$ & - \\
VTMS & $60.1 \pm 1.09$ & $29.3 \pm 0.1$ & $10.6 \pm 0.1$ \\
\hline
\end{tabular}

following maxima were used to carry out an analysis of chemical bonding characteristic for different filler surfaces: $\mathrm{C} 1 s, \mathrm{O} 1 s$, as well as Si $2 p$.

Deconvolution examples of the core-level spectra for plain nanotubes and for nanotubes modified with VTMS are presented in Fig. 16, while Table 4 gives the contribution of particular components of each spectrum. For the non-modified 
Fig. 15 XPS survey spectra of the surfaces of: non-modified MWCNTs (a) and modified with VTMS (b)

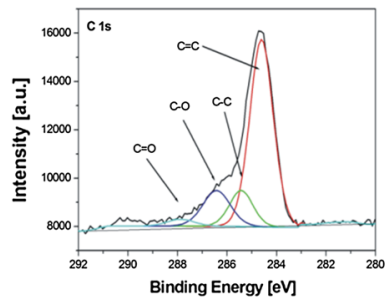

(a)

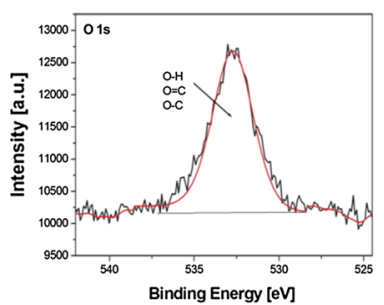

(c)
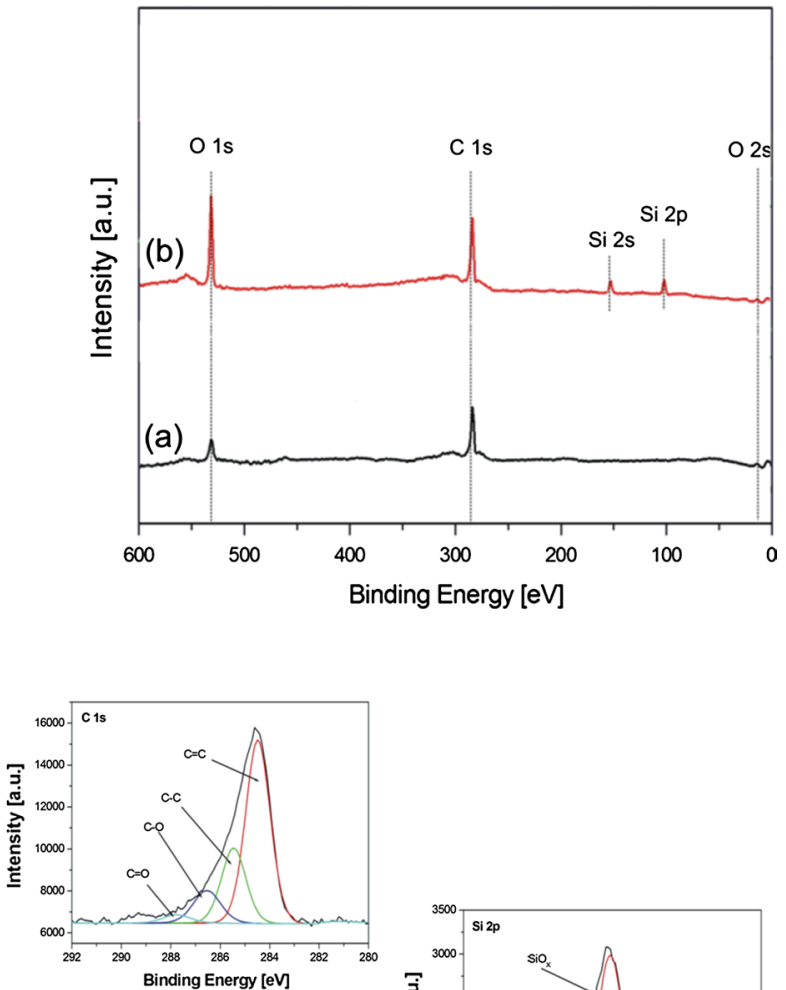

(b)
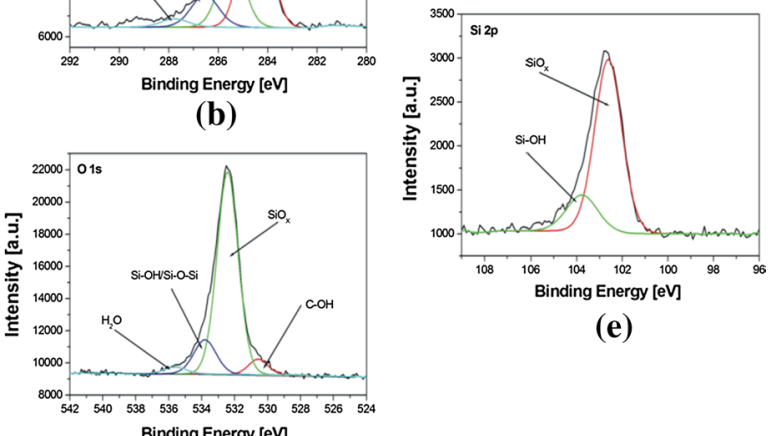

(e)

Fig. 16 Deconvolution examples of the $\mathrm{C} 1 s(\mathbf{a}, \mathbf{b}), \mathrm{O} 1 s(\mathbf{c}, \mathbf{d})$ and $\mathrm{Si} 2 p(\mathbf{e})$ core-level spectra for plain nanotubes (a, c) and for nanotubes modified with VTMS (b, d, e)

MWCNTs, the C $1 s$ spectrum is comprised of bands typical for carbon materials [18, 39-42].

The highest intensity is shown by the maximum at $284.6 \mathrm{eV}$ corresponding to $\mathrm{C}=\mathrm{C}\left(s p^{2}\right)$ bonds. The maximum at $285.4 \mathrm{eV}$ represents $\mathrm{C}-\mathrm{C}\left(s p^{3}\right)$ and/or $\mathrm{C}-\mathrm{H}$ bond. A contribution of the $s p^{2}$ phase is $4 / 5$ times larger than that of the $s p^{3}$ fraction, with this proportion being characteristic for carbon nanotubes. The nanotube surface also contains oxygen atoms present either in a form of $\mathrm{C}-\mathrm{O}$ bonds corresponding to the $286.4 \mathrm{eV}$ band or in carbonyl moieties recorded at the binding energy 
Table 4 Contribution of particular components of the $\mathrm{O} 1 s, \mathrm{C} 1 s$ and Si $2 p$ core-level XPS spectra of plain and modified CNT

\begin{tabular}{|c|c|c|c|c|}
\hline \multirow[t]{2}{*}{ Peak } & \multicolumn{2}{|c|}{ Unmodified CNT } & \multicolumn{2}{|c|}{ Modified with VTMS } \\
\hline & Component & $\begin{array}{l}\text { Contribution of particular } \\
\text { components [\%] }\end{array}$ & Component & $\begin{array}{l}\text { Contribution of } \\
\text { particular components } \\
{[\%]}\end{array}$ \\
\hline \multirow[t]{5}{*}{$\mathrm{C} 1 s$} & $\mathrm{C}=\mathrm{C}$ & 66.8 & $\mathrm{C}=\mathrm{C}$ & 64.2 \\
\hline & $\mathrm{C}-\mathrm{C}$ & 12.9 & $\mathrm{C}-\mathrm{C}$ & 22.9 \\
\hline & $\mathrm{C}-\mathrm{O}$ & 15.0 & $\mathrm{C}-\mathrm{O}$ & 9.7 \\
\hline & $\mathrm{C}=\mathrm{O}$ & 2.9 & $\mathrm{C}=\mathrm{O}$ & 3.1 \\
\hline & $\mathrm{COOH}$ & 2.4 & & \\
\hline \multirow[t]{4}{*}{$\mathrm{O} 1 s$} & $\mathrm{O}-\mathrm{H} / \mathrm{O}=\mathrm{C}$ & 100 & $\mathrm{C}-\mathrm{OH}$ & 5.4 \\
\hline & & & $\mathrm{SiO}_{x}$ & 77.8 \\
\hline & & & $\mathrm{Si}-\mathrm{OH} /$ & 14.0 \\
\hline & & & $\begin{array}{l}\mathrm{Si}-\mathrm{O}-\mathrm{Si} \\
\text { ads. } \mathrm{H}_{2} \mathrm{O}\end{array}$ & 2.8 \\
\hline \multirow[t]{2}{*}{ Si $2 p$} & - & - & $\mathrm{SiO}_{X}$ & 80.6 \\
\hline & & & $\mathrm{Si}-\mathrm{OH}$ & 19.4 \\
\hline
\end{tabular}

of $287.9 \mathrm{eV}$. The lowest intensity band at $290.0 \mathrm{eV}$ is attributed to the presence of carboxyl groups. The presence of oxygen-containing functions is confirmed by the $\mathrm{O} 1 s$ core-level spectrum which contains a single band at $532.7 \mathrm{eV}$ that corresponds to $\mathrm{C}=\mathrm{O}$ and $-\mathrm{OH}$ chemical bonds.

Plasma modification of carbon nanotubes with the organosilicon compound also introduces substantial changes of the content of different chemical moieties on their surface. Energetic conditions in plasma favor a fragmentation of the vinyltrimetoxysilane molecule, with its fragments being bound to the surface modification. XPS core-level C $1 s$ spectrum of the filler modified with VTMS is presented in Fig. 16 As seen in the figure, the majority of chemical bonds found are also present on the non-modified surface, with the difference being quantitative. The amount of $\mathrm{C}=\mathrm{C}$ bonds is decreased by 2 at.\%, with a simultaneous substantial increase in the concentration of the $s p^{3}$ bonding. Double $\mathrm{C}=\mathrm{C}$ bonds are very functional in plasmathey easily break down with the active carbon atoms formed subsequently reacting with the molecular fragments of the modifier molecule. In this way, new $\mathrm{C}-\mathrm{C}$, and also $\mathrm{C}-\mathrm{O}$ and $\mathrm{C}=\mathrm{O}$ bonds are formed on the filler surface what is, indeed, reflected in its XPS core-level C $1 s$ spectrum.

A presence of new chemical moieties formed in the process of plasma surface modification with VTMS is also revealed by the core-level O $1 s$ spectra. In comparison with the oxygen spectrum of a non-modified nanotube surface, three new bands appear after modification. They are: $\mathrm{C}-\mathrm{OH}$ band at $530.6 \mathrm{eV},-\mathrm{O}_{x} \mathrm{Si}$ band at $532.4 \mathrm{eV}$, and $\mathrm{Si}-\mathrm{OH}$ or $\mathrm{Si}-\mathrm{O}-\mathrm{Si}$ band at $533.8 \mathrm{eV}$. The presence of $\mathrm{O}-\mathrm{Si}$ bonds unambiguously points to surface chemical modification of the nanotube filler.

On the basis of the results presented, one can state that surface plasma modification of carbon nanotubes with organosilicon compounds leads to a formation 
of new $-\mathrm{O}-\mathrm{Si}$ bonds at the expense of $\mathrm{C}=\mathrm{C}$ double bonds. What is more, no presence of direct silicon bonding with carbon was observed on these surfaces.

On the basis of the results acquired in this work and in accordance with the literature data [18], one can assume that the mechanism of surface modification of carbon fillers with the chemicals presented may be divided into two stages. Stage one comprises a formation of active sites on the carbon surface with the help of oxygen plasma. Under glow discharge conditions, plasma-formed activated oxygen atoms are bound to carbon surface with the foundation of carbonyl $\mathrm{C}=\mathrm{O}$ and hydroxyl $\mathrm{C}-\mathrm{OH}$ connections. Hydrogen content required for the hydroxyl groups originates either from surface terminal $\mathrm{C}-\mathrm{H}$ bonds or from water adsorbed on that surface.

The second stage of the filler modification process involves the effect of plasma on the molecules of the modifying chemicals. Plasma energy is high enough to bring about a partial fragmentation of these compounds. It is quite reasonable to assume that the resulting fragments of the lowest molecular weight comprise: $\mathrm{Si}, \mathrm{Si}-\mathrm{O}$, and $\mathrm{C}-\mathrm{C}=\mathrm{C}, \mathrm{C}=\mathrm{O}, \mathrm{C}-\mathrm{O}-\mathrm{C}$ moieties as well as short aliphatic groups such as $-\mathrm{CH}_{3}$.

Silicon as one of the elements used in the present work is characterized with a substantial affinity toward oxygen. XPS spectra of the surfaces modified with its compounds indicate that this constituent is bound to the carbon matrix exclusively via oxygen atoms. As far as carbon-containing active fragments are concerned, they are bound to the surface as a consequence of a breakage of the matrix $\mathrm{C}=\mathrm{C}$ double bonds which is specified by an increased concentration of the $\sigma s p^{3}$ carbon-carbon bonds on the expense of $\pi s p^{2}$ carbon-carbon bonds.

The results presented unambiguously show that the plasma chemical treatment of carbon filler surfaces with silanes, combined with oxygen plasma activation of these surfaces, constitutes an effective means of their modification and, therefore, of a manufacture of a new generation of carbon fillers for the elastomer industry.

Carbon nanotube fillers, modified with both silane derivatives, were then used to manufacture rubber vulcanizates. Mechanical properties of these vulcanizates, such as mean stress at $100 \%$ elongation (M100), tensile strength and elongation at break, are presented in Fig. 17.

As seen in the figure, an application of VTMS-modified MWCNTs significantly increases the modulus at $100 \%$ of elongation, as well as elongation at break and tensile strength of rubber vulcanizates. The effect is different for MTMS and VTMS modification. In the case of VTMS-modified MWCNTs, the $100 \%$ elongation modulus increases from 1.23 to 1.52 MPa, while MTMS modification of the filler particles makes this parameter grow only slightly, i.e., up to $1.32 \mathrm{MPa}$. It means that, in a course of polymer processing, grafted MTMS very likely plays a quite different role than VTMS, being involved in cross-linking the matrix in a specific way due to the presence of sulfur containing thiol groups. For all the samples containing modified filler, elongation at break is higher than that of the reference sample, and definitely the best performance has been observed for rubber vulcanizates containing VTMSmodified MWCNT fillers. Maximum tensile strength recorded is $9.52 \mathrm{MPa}$ in this case, while that of the reference sample equals $6.87 \mathrm{MPa}$. Finally, the respective data for the vulcanizates containing oxygen plasma-activated and MTMS-modified MWCNT fillers amount to $8.63 \mathrm{MPa}$ and to $8.80 \mathrm{MPa}$. 


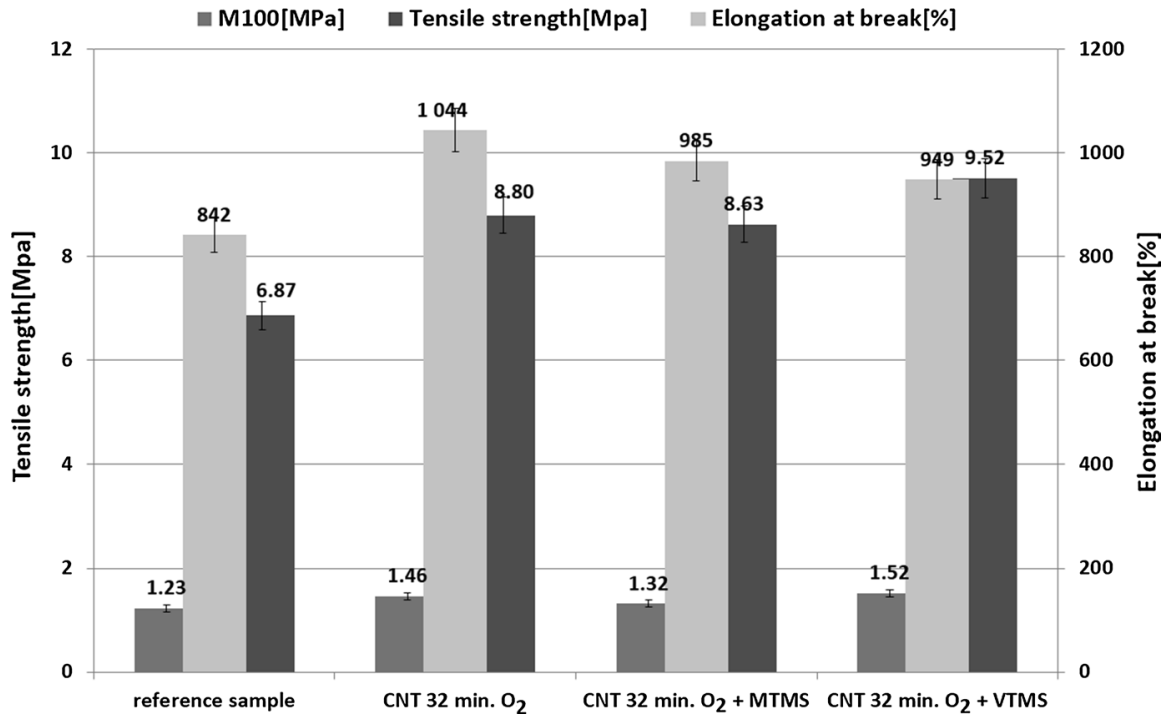

Fig. 17 Mechanical properties of the SBR vulcanizates with silane-modified MWCNT fillers

The influence of silane derivatives grafted on a filler surface is also reflected in mechanical properties of rubber vulcanizates filled with graphene platelets. The results of mechanical property measurements of this group of modified products are presented in Fig. 18.

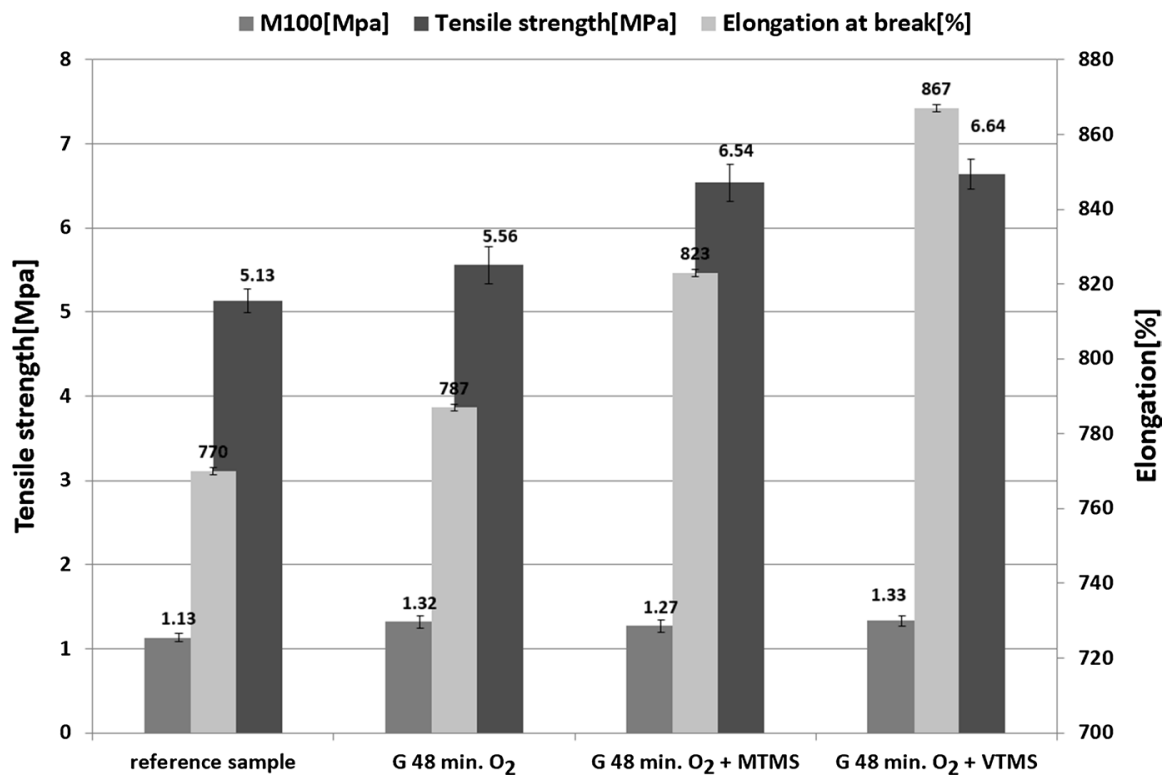

Fig. 18 Mechanical properties of SBR vulcanizates with modified GnP fillers 
As seen in the figure, elongation at break figures for rubber vulcanizates containing fillers modified with silane derivatives are higher than $800 \%$ (823\% for MTMS and $867 \%$ for VTMS modification). The mean value of their tensile strength equals 6.54 $\mathrm{MPa}$ and 6.64 $\mathrm{MPa}$, respectively. An improved performance is also observed for the sample containing oxygen plasma-activated graphene platelets solely. The above results suggests that the improvement achieved is mainly due to the material cleaning and exfoliation effects being observed as a result of plasma treatment of the filler particles.

In order to assess their cross-link density, the vulcanizates were subjected to swelling tests, with the respective data being presented in Fig. 19. These measurements confirm a notion that grafted silanes are involved in cross-linking process. For MWCNT- and GnP-filled vulcanizates, the cross-link densities are significantly higher when the modified filler is used. As far as mercaptotrimethoxysilane is concerned, its sulfur-donating thiol group acts as a cross-linking co-agent. In the case of vinyltrimethoxysilane, the unsaturated vinyl group is also active during the crosslinking process. Both mechanisms lead to a creation of increased amounts of crosslinks in the vulcanized material.

The analysis of filler dispersion in the rubber composite was carried out for both carbon fillers, either non-modified at all, or activated in oxygen plasma and then modified with vinyltrimetoxysilane. The results are presented in Figs. 20, 21, and 22. While Fig. 20 shows images of sample surfaces with the contrasted presence of filler particles, their size distribution is presented in Figs. 21 and 22 for MWCNT and GnP fillers, respectively.

It is clear from the above figures that the treatment significantly alters dispersion of carbon nanotubes and their distribution in the rubber composite. The most important difference between composites containing non-modified and modified MWCNTs is the amount of small agglomerates $(<5 \mu \mathrm{m})$, which are responsible for their strengthening effect. In the case of modified filler, one can also observe a smaller

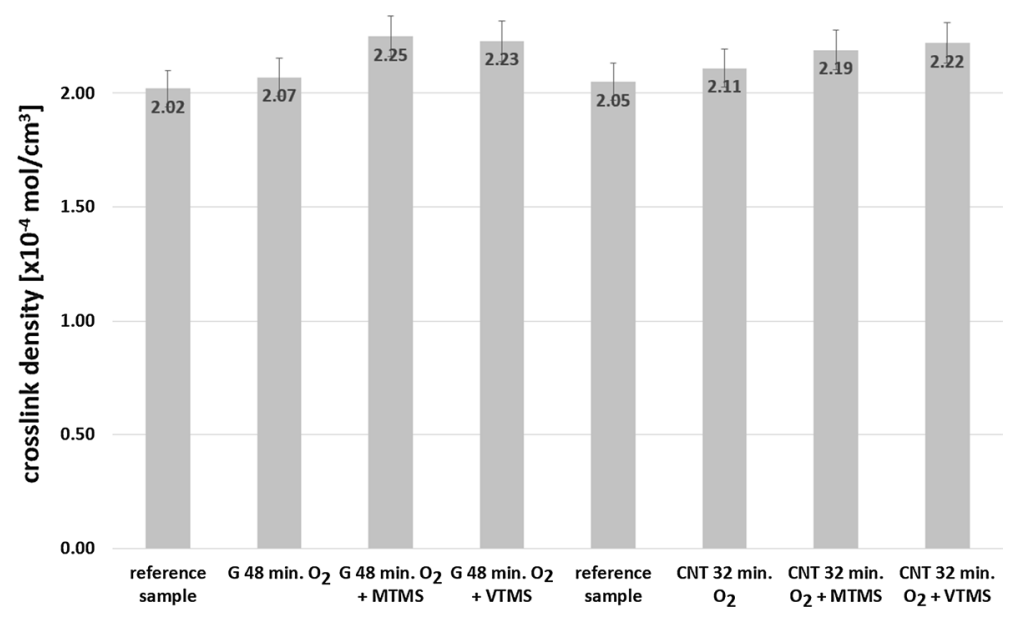

Fig. 19 Cross-link density of the rubber vulcanizates 


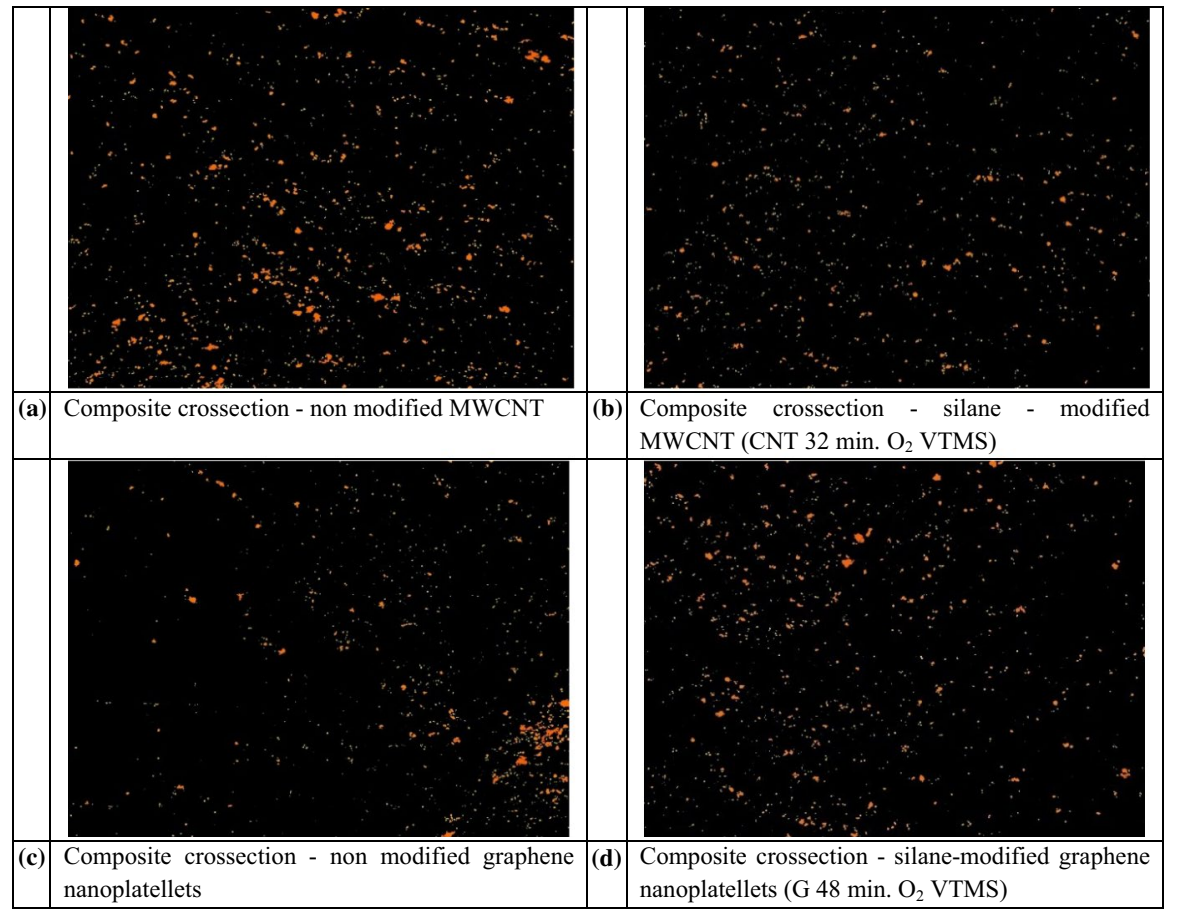

Fig. 20 Crossections of composites containing non-modified (a, c) and VTMS-modified (b, d) carbon fillers

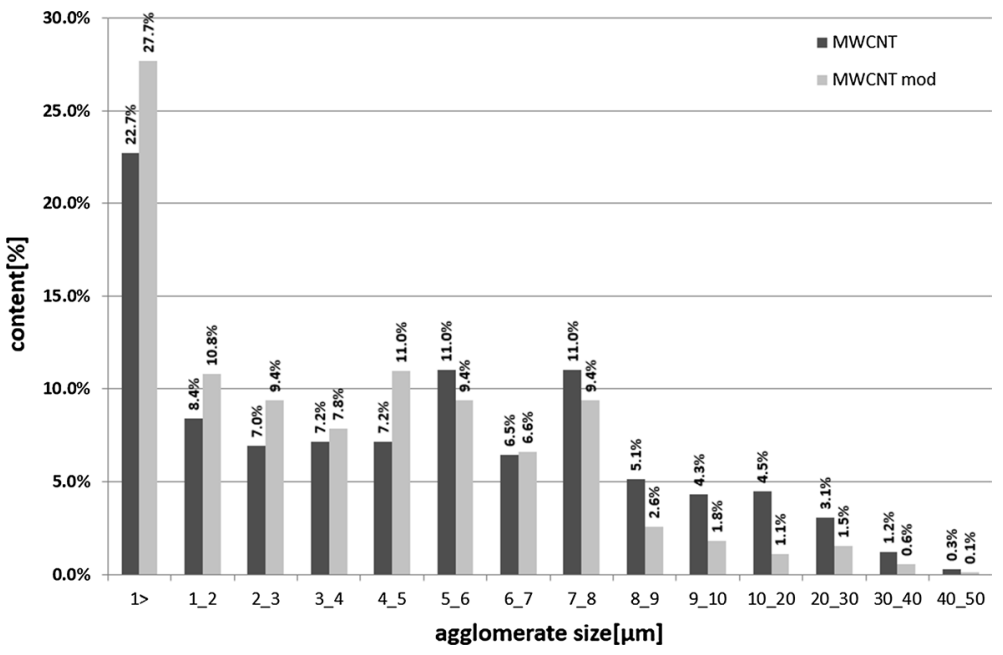

Fig. 21 Size distribution of MWCNT agglomerates in the composite. MWCNT modification: 32 min of $\mathrm{O}_{2}$ plasma treatment followed by modification with VTMS 


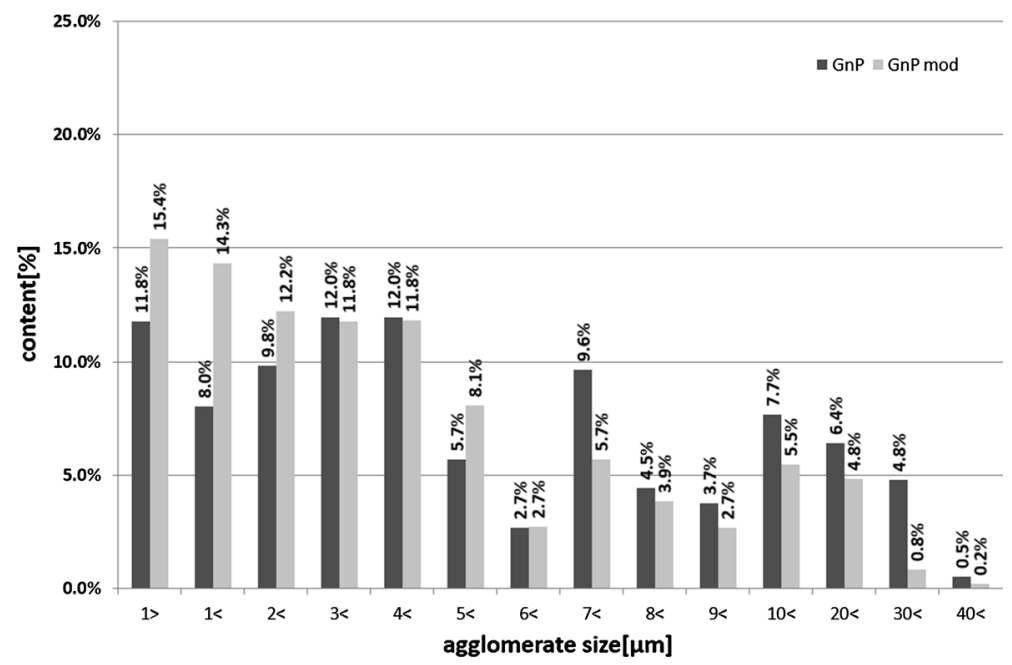

Fig. 22 Size distribution of $\mathrm{GnP}$ agglomerates in the composite. GnP modification: 48 min of $\mathrm{O}_{2}$ plasma treatment followed by modification with VTMS

number of large destructive structures which are considered the weakest spots of a composite. In general, the details of microstructure presented well correspond to the results of mechanical testing that show a major improvement after VTMS grafting.

As far as GnP-filled rubber composites are concerned, an improvement in the filler dispersion following the treatment is less evident than in the case of MWCNT. There is definitely a higher amount of small agglomerates $(<3 \mu \mathrm{m})$ in the treated filler, for which a slight strengthening effect has also been observed during an analysis of their mechanical properties. However, in this case, it appears to be the spatial distribution of $\mathrm{GnP}$ agglomerates that is more important than the degree of their dispersion - it is much better in the case of the modified filler than that of a virgin filler. Finally, when compared to MWCNT containing samples, the GnP-filled composites comprise more large agglomerates resulting from well-known dispersion difficulties in rubber matrix during mixing process.

In the case of VTMS-modified carbon nanotubes, the enhancement of filler dispersion in the composite well corresponds to the results of its mechanical tests. Substantially, larger amounts of agglomerates of average size remaining below $1 \mu \mathrm{m}$ have been observed for the composites based on modified MWCNTs than for those containing unmodified nanotubes, with the respective numbers amounting to $27.7 \%$ and $22.7 \%$. The same concerns agglomerates of the size below $5 \mu \mathrm{m}$ that are beneficial from the viewpoint of the composite structure. A reversed situation is observed in the case of larger agglomerates-their concentration is higher in a composite filled with unmodified nanotubes. The materials where the filler dispersion is better, i.e., those filled with VTMS-modified MWCNTs, are also characterized with higher magnitudes of tensile strength and modulus of elasticity. The same effect for composites filled with the GnPt filler is smaller, but still well observable—an increase in filler dispersion is followed by an improvement in their mechanical properties. 
As revealed by the XPS analysis (Table 3), a modification of carbon nanotubes with VMTS introduces substantial surface concentration of silicon (over 10\%). The results comprise an increase in network density of the composite and an improvement in the filler dispersion both leading to the reinforcement and stiffening of the material.

\section{Activated filler modification with titanates and zirconates}

Of the two types of carbon filler, grafting of titanates and zirconates was carried out for MWCNTs only, as it was considered a more promising substrate. The surface free energy results for grafted filler are presented in Fig. 23.

The above data are not easy to interpret. Complicated reactions take place here, due to the branched structure of the respective compounds with multiple oxygen atoms that are thought to be potentially involved in the modification mechanism. It should be noted that the performance of the composites is also affected by the use of the fillers solely activated with the oxygen plasma. All the treatment processes performed resulted in the decrease in the SFE polar component below the value for the reference sample, what indicates a successful modification. The polar component differences between titanate- and zirconate-modified filler are very small. Apparently, oxygen atoms and unsaturated bonds are more likely involved in the modification process, with hydrocarbon parts of the compounds being exposed to further interactions with rubber macromolecules.

Just as it was in the case of filler modification with silane connections, XPS analysis was carried out for fillers modified with metal-organic compounds. An example of a surface composition of a nanotube filler modified with NZ33 zirconium connection is presented in Fig. 24.

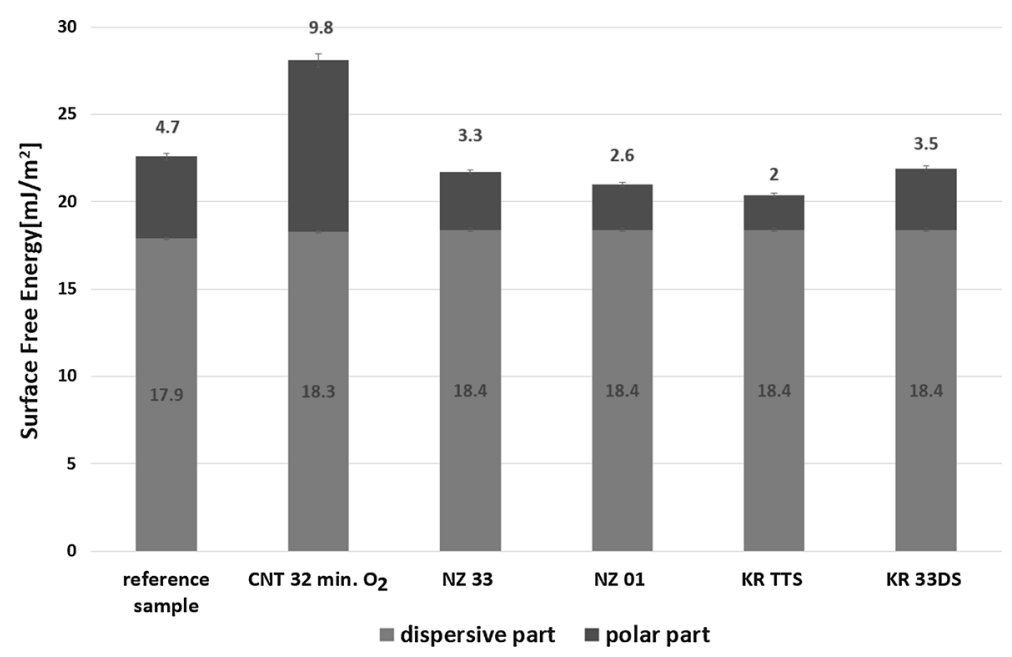

Fig. 23 Surface free energy and its components of titanate/zirconate grafted MWCNTs 
Fig. 24 XPS survey spectra of the surfaces of: non-modified MWCNTs (a), NZ33-modified nanotubes (b)

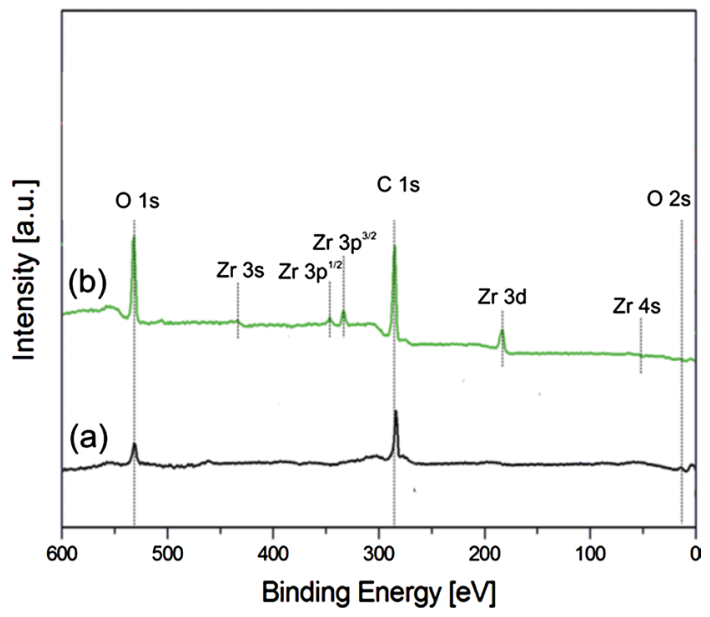

Quantitative results of that analysis are presented in Table 5. In the sample modified with NZ33, a surface content of zirconium amounts to ca. 2.5 at.\%. The results for nonmodified MWCNT filler are also presented here, for the sake of a comparison. The data presented in the table indicate an increase in the amount of oxygen as a result of the modification process, just as it was in the case of silane treatment. After modification, oxygen content amounts to 25.5 at. \%, and this time it can be related to the content of this element in the starting material.

Figure 24 shows examples of XPS survey spectra of the surfaces of: non-modified MWCNTs (a) and NZ33-modified nanotubes (b). A calibration of these spectra was made on the basis of a maximum corresponding to $s p^{2}(\mathrm{C}=\mathrm{C})$ bonds, present at the binding energy of $286.4 \mathrm{eV}$. In the case of zirconate-modified filler, a small maximum appears at the binding energy of $283.6 \mathrm{eV}$. This maximum corresponds to extra $\mathrm{C}=\mathrm{C}$ bonds, very likely originating from the fragments of initial zirconate molecule. Bands characteristic for MWCVTs are described in one of the previous sections presenting results of filler modification with silanes. As far as NZ33-modified nanotubes are concerned, its spectrum contains the following extra bands corresponding to different corelevel electrons of zirconium: $\mathrm{Zr} 3 s$ at ca. $432.2 \mathrm{eV}, \mathrm{Zr} 3 p^{1 / 2}$ at ca. $347.6 \mathrm{eV}, \mathrm{Zr} 3 p^{3 / 2}$ at ca. $332.1 \mathrm{eV}, \mathrm{Zr} 3 d 5 / 2$ at ca. $182.5 \mathrm{eV}, \mathrm{Zr} 3 d 3 / 2$ at ca. $184.9 \mathrm{eV}, \mathrm{Zr} 4 s$ at ca. $53.8 \mathrm{eV}$ and $\mathrm{Zr} 4 p$ at ca. $31.0 \mathrm{eV}$.

Deconvolution examples of the core-level spectra for plain nanotubes (for a comparison) and for nanotubes modified either with NZ33 are presented in Fig. 25, while Table 6 gives the contribution of particular components of each spectrum.

Table 5 XPS data of surface elemental composition of nanotube samples

\begin{tabular}{llll}
\hline Type of modifier & \multicolumn{4}{l}{ Atomic composition of the films [at.\%] } \\
\cline { 2 - 4 } & $\mathrm{C}$ & $\mathrm{O}$ & $\mathrm{Zr}$ \\
\hline 00 & $83.8 \pm 1.60$ & $16.2 \pm 0.6$ & - \\
$\mathrm{NZ33}$ & $72.0 \pm 1.34$ & $25.5 \pm 0.4$ & $2.5 \pm 0.1$ \\
\hline
\end{tabular}




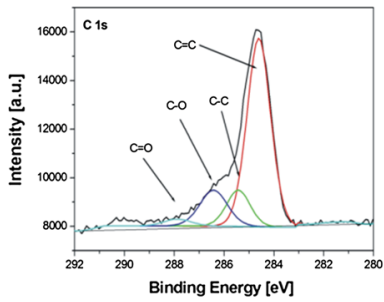

(a)

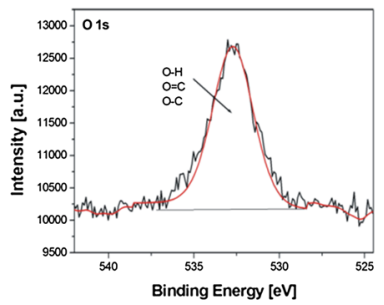

(c)

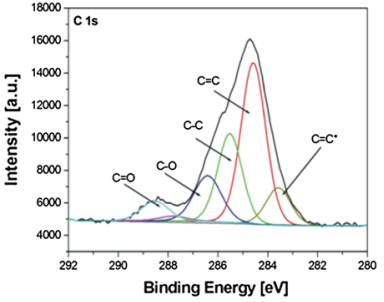

(b)

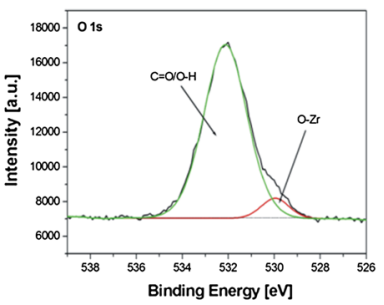

(d)

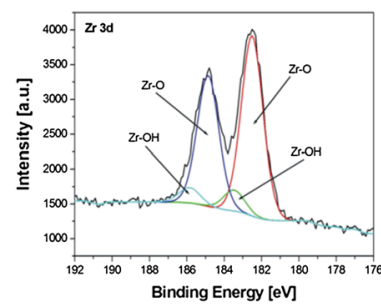

(e)

Fig. 25 Deconvolution examples of the $\mathrm{C} 1 s(\mathbf{a}, \mathbf{b}), \mathrm{O} 1 s(\mathbf{c}, \mathbf{d})$ and $\mathrm{Zr} 3 d$ core-level spectra for plain nanotubes (a, c) and for nanotube modified either with NZ $33(\mathbf{b}, \mathbf{d}, \mathbf{e})$

Table 6 Contribution of particular components of the $\mathrm{O} 1 s, \mathrm{C} 1 s$, and $\mathrm{Zr} 3 d$ core-level XPS spectra of plain and modified CNT

\begin{tabular}{|c|c|c|c|c|}
\hline \multirow[t]{2}{*}{ Peak } & \multicolumn{2}{|c|}{ Unmodified CNT } & \multicolumn{2}{|c|}{ Modified with NZ 33} \\
\hline & Component & $\begin{array}{l}\text { Contribution of particular } \\
\text { components [\%] }\end{array}$ & Component & $\begin{array}{l}\text { Contribution of } \\
\text { particular components } \\
\text { [\%] }\end{array}$ \\
\hline \multirow[t]{5}{*}{$\mathrm{C} 1 s$} & $\mathrm{C}=\mathrm{C}$ & 66.8 & $\mathrm{C}=\mathrm{C}^{*}$ & 7.6 \\
\hline & $\mathrm{C}-\mathrm{C}$ & 12.9 & $\mathrm{C}=\mathrm{C}$ & 39.7 \\
\hline & $\mathrm{C}-\mathrm{O}$ & 15.0 & $\mathrm{C}-\mathrm{C}$ & 25.6 \\
\hline & $\mathrm{C}=\mathrm{O}$ & 2.9 & $\mathrm{C}-\mathrm{O}$ & 20.4 \\
\hline & $\mathrm{COOH}$ & 2.4 & $\mathrm{C}=\mathrm{O}$ & 6.6 \\
\hline \multirow[t]{2}{*}{$\mathrm{O} 1 s$} & $\mathrm{O}-\mathrm{H} / \mathrm{O}=\mathrm{C}$ & 100 & $\mathrm{C}-\mathrm{OH}$ & 93.0 \\
\hline & & & $\mathrm{O}-\mathrm{Zr}$ & 7.0 \\
\hline \multirow[t]{2}{*}{$\mathrm{Zr} 3 d$} & - & - & $\mathrm{Zr}-\mathrm{O}$ & 89.6 \\
\hline & & & $\mathrm{Zr}-\mathrm{OH}$ & 10.4 \\
\hline
\end{tabular}

Carbon modification of nanotubes with metal-organic NZ33 connection results in a formation of extra bonds on their surface. The most characteristic feature is comprised of a substantial decrease in $\mathrm{C}=\mathrm{C}$ bond content, compared to a nonmodified filler. The intensity of the $s p^{3}$ band at the binding energy of $285.4 \mathrm{eV}$, on the other hand, increases for the NZ33-modified surface. Another band that shows a substantially (more than twice) increased intensity in the spectrum of 
zirconate-modified filler is the $286.3 \mathrm{eV}$ band corresponding to $\mathrm{C}-\mathrm{O}$ bonds. Finally, the presence of $\mathrm{C}=\mathrm{O}$ bonds is attributed to the band at $287.9 \mathrm{eV}$.

The XPS O $1 s$ core-level spectrum of MWCNT filler modified with NZ33 zirconate indicates that only $7 \%$ of oxygen is bound to zirconium. The vast majority of its atoms on the surface are present in a form of either $\mathrm{C}=\mathrm{O}$ or $-\mathrm{OH}$ bonds, what is confirmed by the $529.6 \mathrm{eV}$ and $532.1 \mathrm{eV}$ bands, respectively. The notion that zirconium is bonded to oxygen finds its confirmation in the core-level $\mathrm{Zr} 3 d$ spectrum, where the bands at $182.5 \mathrm{eV}$ and at $184.9 \mathrm{eV}$ correspond to the presence of $\mathrm{Zr}-\mathrm{O}$ bonding. Low intensity maxima at 183.5 and at $185.9 \mathrm{eV}$, on the other hand, are attributed to $\mathrm{Zr}-\mathrm{OH}$ connections.

Modification of the filler with NZ33 brings about a slightly different result than the treatment with VTMS does, very likely due to a larger size of a NZ33 molecule and its different affinity toward the cross-linking process. There is no increase of cross-link density observed in that case, probably due to steric hindrance, with an accompanying substantial upsurge of composite elasticity-both elongation at break and tensile strength could not be measured because of an overrunning of the measurement range. A conclusion can, therefore, be drawn that this form of modification also results with a growth of interactions at the polymer matrix-filler interphase.

The effect of titanate/zirconate modification of carbon nanotubes is reflected in the mechanical properties of the rubber nanocomposites, with the respective data being presented in Fig. 26. The results shown are interesting and quite different than those obtained for silane-modified fillers. In all those cases when modified filler was used, the material became much softer and more elastic, with a mean value of the modulus at $100 \%$ of elongation amounting to $0.73-0.80 \mathrm{MPa}$,

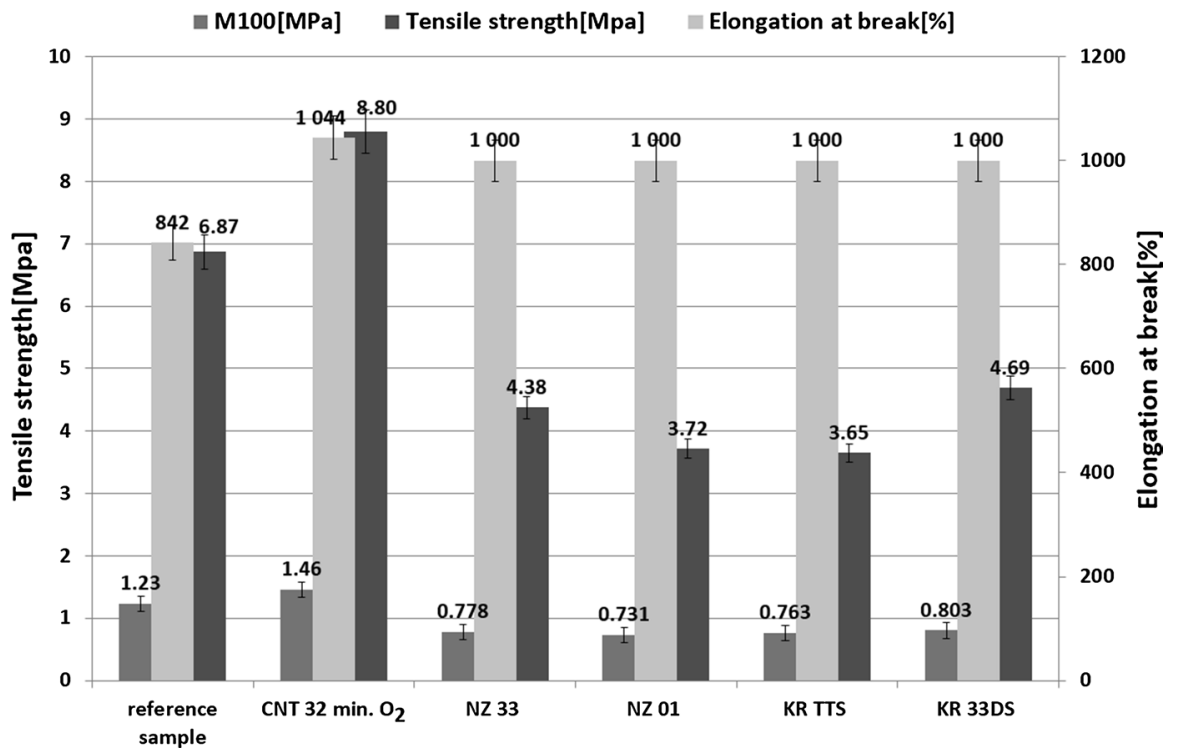

Fig. 26 Mechanical properties of the SBR vulcanizates containing titanate/zirconate grafted MWCNT fillers 
compared to $1.23 \mathrm{MPa}$ for the reference composite and to $1.46 \mathrm{MPa}$ for the oxygen plasma-activated sample. In fact, it was not possible to instigate material breakage, as the elongation exceeded the full scale of the tester $(>1100 \%)$. The data presented correspond to the structure of titanates/zirconates: Rubber vulcanizates become more elastic and softer when more branched compounds and those of higher molecular weight are used as filler modifiers (NZ 01 and KR TTS - see Figs. 3, 4).

The above differences might be explained with the modifier affecting the cross-linking process, and changing filler surface availability for the interactions with polymer macromolecules. The surface of carbon nanotubes is grafted with the compounds (or their fragments after decomposition in plasma) of a branched structure and relatively high volume. As a result, a rubber macromolecule is not able to closely interact with a filler surface with grafted species acting as spacers.

As far as the cross-linking mechanism is concerned, swelling tests and crosslink density results shown in Fig. 27 indicate that the modification only vaguely affects these parameters. Keeping in mind that nanocomposite elongation at break is much higher in the case of titanate-/zirconate-modified fillers, one comes to a conclusion that some additional effects having an influence on the material performance must be present. It may be speculated that the titanate/zirconate incorporation primarily leads to the changes in the cross-link structure and not its density. It is well known, for instance, that in the case of longer cross-links lower modulus and higher elongation at break values of a rubber composite are observed. In our case, such effect is also very likely responsible for the observed phenomenacross-link density has the highest value for the samples filled with MWCNTs modified with compounds containing relatively more unsaturated bonds (NZ 33 and KR 33DS). Such bonds may be active in the cross-linking process as it was observed for carbon nanotubes modification with vinyltrimethoxysilane.

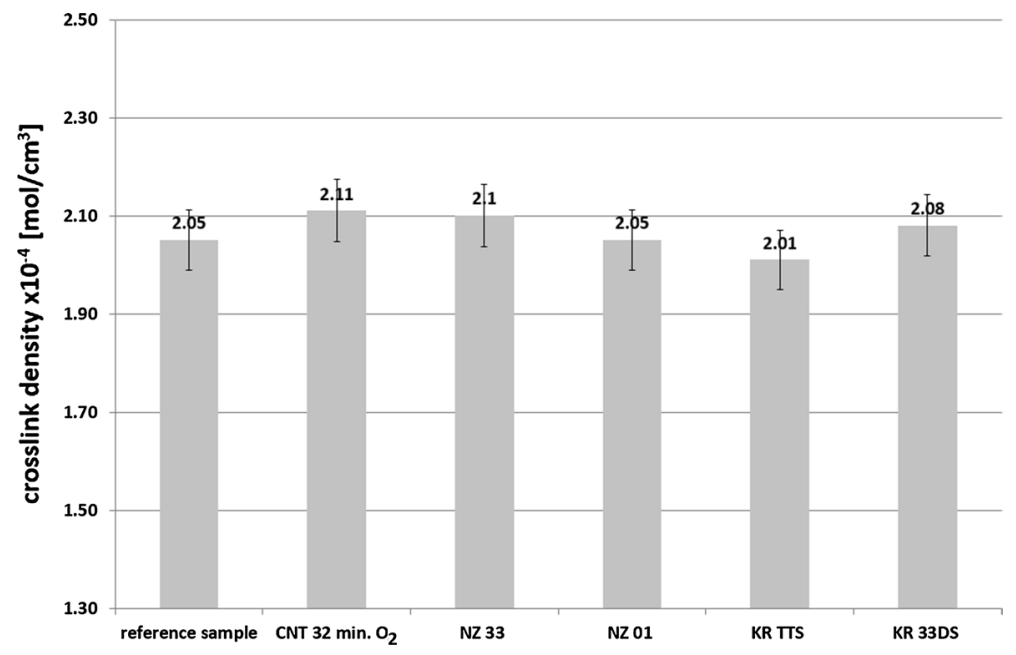

Fig. 27 Cross-link density of the rubber vulcanizates containing MWCNT fillers grafted with titanates/ zirconates 


\section{Conclusions}

On the basis of the results presented above, the following conclusions may be formulated. First of all, the study has shown that it is possible to substantially increase surface free energy of carbon nanotubes with low-temperature oxygen plasma. When it comes to graphene nanoplatellets, however, it is much harder to achieve a similar level of modification. As an effect of the treatment, substantial changes in filler microstructure as well as chemical composition of its surface are observed. Therefore, modification of filler surface affects rubber-filler and filler-filler interactions which have a great impact on the properties of rubber composites.

As far as silane/titanate/zirconate plasma processing of the filler is concerned, it proves to be an effective tool for the functionalization of carbon nanotubes. In the case of graphene nanoplatellets the effect is much weaker due to the more stable structure and smaller amount of active polar and radical centers generated during the plasma activation stage. By involving the filler in a cross-linking process of the rubber composite, it is possible to achieve an improved composite performance. The effects of modification were confirmed with the ToF-SIMS, SEM-EDX, XPS as well as with swelling and mechanical tests.

Acknowledgements The project was funded by the National Science Centre Poland (NCN) conferred on the basis of the Decision Number DEC-2012/05/B/ST8/02922.

Author contributions MS conceived and designed the experiments; MS, AP, and TG performed the experiments; MS and DB analyzed the data; MS and TG contributed reagents/materials/analysis tools; MS wrote the paper, and HS was entirely responsible for its revised version.

\section{Compliance with ethical standards}

Conflict of interest The authors declare no conflict of interest.

Open Access This article is distributed under the terms of the Creative Commons Attribution 4.0 International License (http://creativecommons.org/licenses/by/4.0/), which permits unrestricted use, distribution, and reproduction in any medium, provided you give appropriate credit to the original author(s) and the source, provide a link to the Creative Commons license, and indicate if changes were made.

\section{References}

1. Popov VN (2004) Carbon nanotubes: properties and application. Mater Sci Eng R Rep 43:61-102. https://doi.org/10.1016/j.mser.2003.10.001

2. Spitalsky Z, Tasis D, Papagelis K, Galiotis C (2010) Carbon nanotube-polymer composites: chemistry, processing, mechanical and electrical properties. Prog Polym Sci 35:357-401. https://doi. org/10.1016/j.progpolymsci.2009.09.003

3. Wolff S, Wang J (1992) Filler-elastomer interactions. Part IV. The effect of the surface energies of fillers on elastomer reinforcement. Rubber Chem Technol 65:329-342. https://doi. org/10.5254/1.3538615

4. Dierkes WK, Guo R, Mathew T, Tiwari M, Datta RN, Talma AG, Noordemeer JWM, van Ooij WJ (2011) A key to enhancement of compatibility and dispersion in elastomer blends. Kautsch Gummi Kunstst 64:28-35 (PERI:(DE-600)2089291-3) 
5. http://famastechnology.com/pdf/filler_treatment_with_famasil_silanes_and_titanates.pdf. Accessed 11 May 2018

6. Salvatore JM (2002) Neoalkoxy Titanate and Zirconate coupling agent additives in thermoplastics. Polym Polym Compos 10(2):121-172. https://doi.org/10.1177/096739110201000202

7. Nah C, Huh M-Y, Rhee JM, Yoon TM (2002) Plasma surface modification of silica and its effect on properties of styrene-butadiene rubber compound. Polym Int 51:510

8. Matthew D, Huh M-Y, Rhee JM, Lee M-H, Nah C (2004) Improvement of properties of silicafilled styrene-butadiene rubber composites through plasma surface modification of silica. Polym Adv Technol 15:400

9. van Ooij WJ, Zhang N, Guo S (1999) Surface modification of micronized powders by plasma polymerization process. In: Blitz JP, Little CB (eds) Fundamental and applied aspects of chemically modified surfaces. Royal Society of Chemistry, Cambridge, pp 191-211

10. Zhang N (2000) Surface modification of micronized powders by plasma polymerization process. Master thesis, Division of Research and Advanced Studies, University of Cincinatti, Cincinatti, USA

11. Minchitha KU, Rekha M, Nagaraju N, Kathyayini N (2016) Evaluation of catalytic activity of acid activated multiwalled carbon nanotubes in an esterification reaction. Curr Catal 5:20-30. https://doi.org/10.2174/2211544703666141119220811

12. Osorio AG, Silveira ICL, Bueno VL, Bergmann CP (2008) $\mathrm{H}_{2} \mathrm{SO}_{4} / \mathrm{HNO}_{3} / \mathrm{HCl}$-functionalization and its effect on dispersion of carbon nanotubes in aqueous media. Appl Surf Sci 255:24852489. https://doi.org/10.1016/j.apsusc.2008.07.144

13. Pastine SJ, Okawa D, Kessler B, Polandi M, Lorente M, Zettl A, Frechet JM (2008) A facile and patternable method for the surface modification of carbon nanotubes forests using perfluoroarylazides. J Am Chem Soc 130:4238-4239. https://doi.org/10.1021/ja8003446

14. Li J, Tang T, Zhang X, Li S, Li M (2007) Dissolution, characterization and photofunctionalization of carbon nanotubes. Mater Lett 61:4351-4353. https://doi.org/10.1016/j.matlet.2007.01.103

15. Homenick CM, Sivasubramaniam U, Adronov A (2008) Effect of polymer chain length on the solubility of polystyrene grafted single-walled carbon nanotubes in tetrahydrofuran. Polym Int 57:1007-1011

16. Blake R, Coleman JN, Byrne MT, McCarthy JE, Perova TS, Blau WJ, Fonseca A, Nagy JB, Gun'ko YK (2006) Reinforcement of poly(vinyl chloride) and polystyrene using chlorinated polypropylene grafted carbon nanotubes. J Mater Chem 16:4206-4213

17. Nabarun R, Rajatendu S, Bhowmick A (2012) Modifications of carbon for polymer composites and nanocomposites. Prog Polym Sci 37:781-819

18. Xu T, Yang J, Liu J, Fu Q (2007) Surface modification of multi-walled carbon nanotubes by $\mathrm{O}_{2}$ plasma. Appl Surf Sci 253:8945-8951. https://doi.org/10.1016/j.apsusc.2007.05.028

19. Siciński M, Bieliński D, Gozdek T, Piątkowska A, Kleczewska J, Kwiatos K (2013) Kompozyty elastomerowe $\mathrm{z}$ dodatkiem grafenu lub MWCNT modyfikowanych plazmochemicznie. Inżynieria Materiałowa 34:854-858 (YADDA:bwmeta1.element. baztech-c53d27a5-7274-4b08-9937-4deab850d0e6)

20. Bieliński D, Parys G, Szymanowski H (2012) Plazmochemiczna modyfikacja powierzchni sadzy jako napełniacza mieszanek gumowych. Przem Chem 91:1508-1512

21. Tseng C-H, Wang C-C, Chen C-Y (2007) functionalizing carbon nanotubes by plasma modification for the preparation of covalent-integrated epoxy composites. Chem Mater 19:308-315. https ://doi.org/10.1021/cm062277p

22. Yang K, Gu M, Guo Y, Pan X, Mu G (2009) Effect of carbon nanotube functionalization on the mechanical and thermal properties of epoxy. Carbon 47:1723-1737. https://doi.org/10.1016/j. carbon.2009.02.029

23. Ávila-Orta CA, Cruz-Delgado VJ, Neira-Velázquez MG, Hernández-Hernández E, MéndezPadilla MG, Medellín-Rodríguez FJ (2009) Surface modification of carbon nanotubes with ethylene glycol plasma. Carbon 47:1916-1921. https://doi.org/10.1016/j.carbon.2009.02.033

24. Chen I-H, Wang C-C, Chen C-Y (2010) Preparation of carbon nanotube (CNT) composites by polymer functionalized CNT under plasma treatment. Plasma Process Polym 7:59-63. https:// doi.org/10.1002/ppap.200900067

25. Shenogin S, Bodapati A, Xue L, Ozisik R, Keblinski P (2004) Effect of chemical functionalization on thermal transport of carbon nanotube composites. Appl Phys Lett 85:2229-2231. https:// doi.org/10.1063/1.1794370 
26. Cheng $\mathrm{Y}$, Ko $\mathrm{H}$, Chou S, Ku P (2014) Study on $\mathrm{NH}_{3}$ plasma-treated polyimide/MWNT composites on electrical and surface properties. Mater Sci Appl 5:54-58. https://doi.org/10.4236/ msa.2014.51008

27. Ma PC, Kim JK, Tang BZ (2009) Functionalization of carbon nanotubes using a silane coupling agent. Carbon 44:3232-3238. https://doi.org/10.1016/j.carbon.2006.06.032

28. Valentini L, Puglia D, Carniato F, Boccaleri E, Marchese L, Kenny KM (2008) Use of plasma fluorinated single-walled carbon nanotubes for the preparation of nanocomposites with epoxy Matrix. Compos Sci Technol 68:1008-1014. https://doi.org/10.1016/j.compscitech.2007.07.011

29. Chou W-J, Wang C-C, Chen C-Y (2008) Characteristics of polyimide-based nanocomposites containing plasma modified multi-walled carbon nanotubes. Compos Sci Technol 68:2208-2213. https ://doi.org/10.1016/j.compscitech.2008.04.008

30. Ahn KS, Kim JS, Kim CO, Hong JP (2003) Non-reactive rf treatment of multiwall carbon nanotube with inert argon plasma for enhanced field emission. Carbon 41:2481-2485. https://doi.org/10.1016/ S0008-6223(03)00294-X

31. Gilman AB, Yablokov MY, Kuznetsov AA (2012) Modification of carbon nano objects in low temperature plasma for use in polymer nanocomposites. High Energy Chem 46:219-228. https://doi. org/10.1134/S0018143912040078

32. Hernández Hernández E, Neira Velázquez MG, Ramos-de Valle LF (2009) Surface modification of CNFs via deposition of an ultra-thin coating of plasma polymerized poly (acrylic acid) and its effect on the properties of PA6/CNF nanocomposites. J Appl Polym Sci 112:3510-3518. https://doi. org/10.1002/app.29932

33. Gonzalez Morones P, Avila Orta CA, Navarro Rodriguez D, Neira Velazquez MG (2013) Control of the chemical composition and thickness of deposited coatings over carbon nanotubes using acrylic acid plasma. Afinidad 563:201-205 (RACO:269681)

34. Hernández-Hernández E, Neira-Velázquez MG, Ramos-de Valle LF, Ponce A, Weinkauf D (2010) Changing the surface characteristics of $\mathrm{CNF}$, from hydrophobic to hydrophilic, via plasma polymerization with acrylic acid. J Nano Res 9:45-53. https://doi.org/10.4028/www.scientific.net/JNano R.9.45

35. María G, Neira-Velázquez MG, Hernández-Hernández E, Ramos-de Valle LF, Ávila-Orta CA, Perera-Mercado YA, Solís-Rosales SG, González-Morones P, Ponce-Pedraza A, Ávalos-Borja M, Narro-Céspedes RI, Bartolo-Pérez P (2013) Chemical modification of carbon nanofibers with plasma of acrylic acid. Plasma Process Polym 10:627-633. https://doi.org/10.1002/ppap.201200122

36. Owens DK, Wendt RC (1969) Estimation of the surface free energy of polymers. J Appl Polym Sci 13:1741-1747. https://doi.org/10.1002/app.1969.070130815

37. Flory PJ, Rehner J Jr (1943) Statistical mechanics of crosslinked polymer networks II. Swelling. J Chem Phys. https://doi.org/10.1063/1.1723792

38. Oliver WC, Pharr GM (2009) An improved technique for determining hardness and elastic modulus using load and displacement indentation experiments. J Mater Res 7:1564-1583. https://doi. org/10.1557/JMR.1992.1564

39. Reiche S, Blume R, Zhao XC, Su D, Kunkes E, Behrens M, Schlo R (2014) Reactivity of mesoporous carbon against water: an in situ XPS study. Carbon 77:175-183

40. Lee D, Choi J, Shin J, Jung M, Song S, Suh J, Lee C (2018) Plasma functionalization of powdery nanomaterials using porous filter electrode and sample circulation. Appl Surf Sci 443:628-634

41. Uznanski P, Glebocki B, Walkiewicz-Pietrzykowska A, Zakrzewska J, Wrobel AM, Balcerzak J, Tyczkowski J (2018) Surface modification of silicon oxycarbide films produced by remote hydrogen microwave plasma chemical vapour deposition from tetramethyldisiloxane prekursor. Surf Coat Technol 350:686-698

42. Petrik P, Sulyoka A, Novotny T, Perez-Feróa E, Kalasa B, Agocsa E, Lohnera T, Lehninger D, Khomenkova L, Nagya R, Heitmann J, Menyharda M, Hózera Z (2017) Optical properties of Zr and $\mathrm{ZrO}_{2}$. Appl Surf Sci 421:744-747

Publisher's Note Springer Nature remains neutral with regard to jurisdictional claims in published maps and institutional affiliations. 


\section{Affiliations}

\section{Mariusz Siciński ${ }^{1}$ (D) Dariusz M. Bieliński ${ }^{1} \cdot$ Hieronim Szymanowski ${ }^{2}$.}

Tomasz Gozdek ${ }^{1}$ - Anna Piątkowska ${ }^{3}$

1 Institute of Polymer and Dye Technology, Lodz University of Technology, Stefanowskiego St. 12/16, 90-924 Lodz, Poland

2 Institute of Materials Science and Engineering, Lodz University of Technology, Stefanowskiego St. 1/15, 90-924 Lodz, Poland

3 Institute of Electronic Materials Technology, Wólczyńska St. 133, 01-919 Warsaw, Poland 